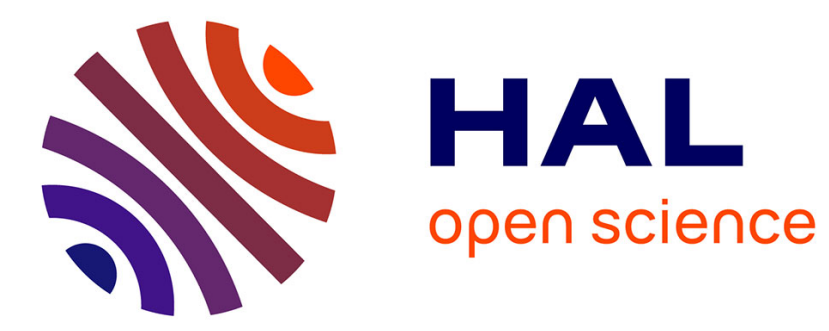

\title{
Two pathways for cysteine biosynthesis in Leishmania major
}

Roderick a M Williams, Gareth D Westrop, Graham H Coombs

\section{To cite this version:}

Roderick a M Williams, Gareth D Westrop, Graham H Coombs. Two pathways for cysteine biosynthesis in Leishmania major. Biochemical Journal, 2009, 420 (3), pp.451-462. 10.1042/BJ20082441. hal-00479145

\section{HAL Id: hal-00479145 \\ https://hal.science/hal-00479145}

Submitted on 30 Apr 2010

HAL is a multi-disciplinary open access archive for the deposit and dissemination of scientific research documents, whether they are published or not. The documents may come from teaching and research institutions in France or abroad, or from public or private research centers.
L'archive ouverte pluridisciplinaire HAL, est destinée au dépôt et à la diffusion de documents scientifiques de niveau recherche, publiés ou non, émanant des établissements d'enseignement et de recherche français ou étrangers, des laboratoires publics ou privés. 
Two pathways for cysteine biosynthesis in Leishmana major

Roderick A. M. Williams, Gareth D. Westrop \& Graham H. Coombs

Strathclyde Institute of Pharmacy and Biomedical Sciences, University of Strathclyde, Glasgow, G4 0NR, UK

Correspondence to: Graham H. Coombs (graham.coombs@strath.ac.uk)

Page heading title: Cysteine biosynthesis in Leishmania

Keywords: Leishmania, protozoan parasite, cysteine biosynthesis, cysteine synthase, cystathionine $\beta$-synthase

Abbreviations: RTS, reverse transulfuation; CS, cysteine synthase; SAT, serine acetyltransferase; CBS, cystathionine $\beta$-synthase; CGL, cystathionine $\gamma$-lyase; MST, mercaptopyruvate sulfurtransferase; 3-MP, 3-mercaptopyruvate; OAS, Oacetylserine; Lmj, Leishmania major; Tc, Trypanosoma cruzi; Hs, Homo sapiens; Sc, Saccharomyces cerevisiae; At, Arabidopsis thialiana; Tv, Trichomonas vaginalis; PLP, pyridoxal 5-phosphate; SS, serine sulfhydrase. 


\section{Synopsis}

Genome mining and biochemical analyses have shown that L. major possesses two pathways for cysteine synthesis - the de novo biosynthesis pathway comprising serine acetyltransferase (SAT) and cysteine synthase (CS) and the reverse transsulfuration (RTS) pathway comprising cystathionine $\beta$-synthase (CBS) and cystathionine gamma-lyase (CGL). The L. major CS (LmjCS) is similar to the type A CSs of bacteria and catalyses the synthesis of cysteine using O-acetyserine and sulfide with $\mathrm{K}_{\mathrm{m}} \mathrm{s}$ of 17.5 and $0.13 \mathrm{mM}$, respectively. LmjCS can use sulfide provided by the action of mercaptopyruvate sulfurtransferase (MST) on 3-mercaptopyruvate (3-MP). LmjCS forms a bi-enzyme complex with Leishmania SAT (and Arabidopsis SAT), with residues K222, H226 and K227 of LmjCS being involved in the complex formation. LmjCBS catalyses the synthesis of cystathionine from homocysteine, but, unlike CBS of mammals, also has high cysteine synthase activity (but with the $\mathrm{K}_{\mathrm{m}}$ for sulfide being $10.7 \mathrm{mM}$ ). In contrast, LmjCS does not have CBS activity. CS was upregulated when promastigotes are grown in medium with limited availability of sulfur amino acids. Exogenous methionine stimulated growth under these conditions and also the levels of intracellular cysteine, glutathione and trypanothione, whereas cysteine had no effect on growth or the intracellular cysteine levels; correlating with the low rate of transport of cysteine into the cell. These data suggest that cysteine is generated endogenously by promastigotes of Leishmania. The absence of CS from mammals and the clear differences between CBS of mammals and Leishmania suggest that each of the parasite enzymes could be a viable drug target.

\section{Introduction}

Leishmania is a protozoan parasite that is the causative agent of a spectrum of diseases collectively known as the leishmaniases, there being some 60000 new cases annually [1]. Some aspects of the metabolism of Leishmania have been investigated in detail [2] notably that involving the low molecular weight thiol trypanothione, a conjugate of glutathione (GSH) and spermidine, which appears to play a pivotal role in maintaining intracellular redox homeostasis and providing defence against oxidative stress [3]. The synthesis of glutathione and so trypanothione depends on the availability of cysteine. This sulfur-containing amino acid is an essential growth factor for the related trypanosomatid Trypanosoma brucei [4] whereas T. cruzi can generate it from homocysteine [5]. In contrast, it is synthesised de novo in the microaerophilic parasitic protozoa Entamoeba, Giardia and Trichomonas - in which cysteine itself is the key antioxidant and redox buffer [6,7]. This study was undertaken to establish how Leishmania obtains cysteine and to characterise the mechanisms involved.

There are two routes known for the generation of cysteine, the de novo biosynthesis pathway, otherwise called the sulfhydrylase pathway [7], and the reverse transsulfuration pathway (RTS) that converts homocysteine to cysteine in two steps catalysed by cystathionine $\beta$-synthase (CBS, EC 4.2.1.22) and cystathionine $\gamma$-lyase (CGL, EC 4.4.1.1) (RTS; see Figure 1) [8]. Mammals contain only the latter pathway, but the situation is more complex in other groups. The de novo biosynthetic pathway for cysteine also comprises two steps, catalysed by serine acetyltransferase (SAT, EC 2.3.1.30) and cysteine synthase (CS, EC 4.2.99.8). In plants, distinct isoforms of SAT and CS exist in the mitochondria, plastids, and cytosol [9], while 
bacteria contain only one isoform of SAT and CS although there are two types of the latter - designated CS type A (CS-A) and CS type B (CS-B) [10]. SAT, CS and CBS activities have been identified in T. cruzi, but only the genes for SAT and CBS have been described [5], whereas E. histolytica contains multiple genes for SAT and CS [6]. T. vaginalis also has multiple type B CS genes but lacks the SAT gene; instead it uses phosphoserine as the precursor for synthesis of cysteine [11].

We had identified genes apparently encoding SAT and CS in Leishmania [12], but the genome also contains genes encoding all four enzymes of the transsulfuration pathway (both forward and reverse). Thus the in silico evidence suggested a functional redundancy in Leishmania for the generation of cysteine. The aim of this study was to determine whether or not the predicted enzymes function as postulated and to characterise those that do. Moreover, we wished to determine the interplay between to two routes whereby cysteine may be synthesised, to investigate how they may be regulated to control cysteine homeostasis, and whether uptake of exogenous cysteine is also important. One notable way in which biosynthesis of cysteine is controlled in some organisms is through complex formation between SAT and CS, thus the potential for such complex formation in Leishmania has been studied. As mammals lack the de novo biosynthesis of cysteine, this pathway, if operational and important in Leishmania, could be exploitable as a drug target.

\section{Experimental}

Strains and cultivation of $L$. major - Promastigotes of $L$. major (MHOM/IL/80/Friedlin) were used throughout this study. They were grown at $27^{\circ} \mathrm{C}$ in either Modified Eagle's Medium designated HOMEM (Gibco, UK) supplemented with $10 \%(\mathrm{v} / \mathrm{v})$ heat-inactivated fetal bovine serum (FCS) for routine maintenance [12] or, for the experiments investigating the use of exogenous organic sulphur sources, in Sulphur Depleted Medium (designated SDM) comprising Minimum Essential Medium (MEM) (ICN-biomedical) without an exogenous sulfur source (none of cysteine, cystine, methionine and serine) and supplemented with $20 \%(\mathrm{v} / \mathrm{v})$ dialysed heat inactivated fetal calf serum (dHiFCS) (Sigma-Aldrich, UK), D-glucose (1000 mg. $\left.\mathrm{L}^{-1}\right)$, glutathione $\left(0.10 \mathrm{mg} . \mathrm{L}^{-1}\right)$, hypoxanthine $\left(0.70 \mathrm{mg} . \mathrm{L}^{-1}\right)$, thiamine $(0.6$ mg. $\left.\mathrm{L}^{-1}\right)$, uracil $\left(0.6 \mathrm{mg} . \mathrm{L}^{-1}\right)$, alanine $\left(50 \mathrm{mg} . \mathrm{L}^{-1}\right)$, aspartic acid $\left(0.06 \mathrm{mg} . \mathrm{L}^{-1}\right)$, glutamic acid $\left(0.14 \mathrm{mg} . \mathrm{L}^{-1}\right)$, glutamine $\left(0.02 \mathrm{mg} . \mathrm{L}^{-1}\right)$, proline $\left(0.08 \mathrm{mg} . \mathrm{L}^{-1}\right)$, haemin $(0.035$ mg. $\left.\mathrm{L}^{-1}\right)$ and folic acid $\left(0.02 \mathrm{mg} . \mathrm{L}^{-1}\right)$ or in RPMI 1640 without cystine and methionine (Sigma) and supplemented with $\mathrm{MgCl}_{2}\left(0.1\right.$ g. $\left.\mathrm{L}^{-1}\right)$, HEPES pH $7.2(40 \mathrm{mM})$, biopterin $\left(5 \mu \mathrm{g} \cdot \mathrm{ml}^{-1}\right)$, hemin $(1 \% \mathrm{v} / \mathrm{v})$ and $20 \%(\mathrm{v} / \mathrm{v}) \mathrm{dHiFCS}$. The sulfur source required for growth of $L$. major promastigotes was investigated by adding methionine $(300 \mu \mathrm{M})$, cysteine $(300 \mu \mathrm{M})$, homocysteine $(300 \mu \mathrm{M})$, serine $(280 \mu \mathrm{M})$, O-acetylserine $(250$ $\mu \mathrm{M})$ or sodium sulfide $(80 \mu \mathrm{M})$ with and without serine $(300 \mu \mathrm{M})$. The medium without an exogenous sulfur source acted as the control in these experiments. Cell densities were estimated using an improved Neubauer hemocytometer.

Identification and cloning of SAT, CS, and CBS of $L$. major - The genome database for L. major (http://www.ebi.ac.uk/Tools/blast2/parasites.html) was searched using the TBLASTN algorithm with protein sequences involved in cysteine de novo biosynthesis and RTS pathways from bacteria, yeast, plants and parasitic protozoa as queries to identify putative L. major proteins involved in these pathways. Expectation values (E-value) of the TBLASTN output, amino acid sequence alignments, and 
identification of putative key domains known to be key components for enzymatic activities were all studied to determine if there was significant orthology. The Leishmania proteins identified were assigned as orthologues potentially involved in cysteine biosynthesis and have been annotated in www.geneDB.org with the systematic names serine acetyltransferase (SAT, LmjF43.2850), cysteine synthase (CS, LmjF36.3590), cystathionine $\gamma$-lyase (CGL, LmjF35.3230); cystathionine $\beta$ synthase (CBS; LmjF17.0250). Enzymes potentially comprising a forward transsulfuration pathway were also identified and annotated as CBL (LmjF32.2640) and CGS (LmjF14.0460).

Genomic DNA (gDNA) of L. major was isolated as described by [13]. The open reading frames (ORFs) of the genes putatively involved in the L. major cysteine synthesis pathways were amplified by PCR using the Expand High Fidelity PCR system (Roche Molecular Biochemicals) with gene-specific primers modified with appropriate restriction sites (to facilitate cloning into their respective expression vectors) detailed in Table S1. All PCR assays were carried out in a GeneAmp 9600 PCR system (PerkinElmer Life Sciences) for 30 cycles of denaturation $\left(94^{\circ} \mathrm{C}, 15 \mathrm{~s}\right)$, annealing $\left(65^{\circ} \mathrm{C}, 15 \mathrm{~s}\right)$ and extension $\left(72^{\circ} \mathrm{C}, 2 \mathrm{~min}\right)$. Each ORF was verified by nucleotide sequencing (MBSU, University of Glasgow, UK) and cloned into the pET expression vectors (Invitrogen) pre-digested with appropriate restriction enzymes to produce the plasmids detailed in Table S1. The plasmids were used to transform BL21(DE3) for recombinant protein expression to generate recombinant fusion proteins containing a $6 x$ His-tag, which facilitates purification using affinity chromatography.

Protein expression and purification - L. major SAT, CS and CBS were expressed from a clone of BL21(DE3) transformed with their respective plasmids (Table S1). Overnight cultures in Luria Bertani (LB) medium were used to inoculate fresh LB supplemented with $100 \mu \mathrm{g} \mathrm{ml}^{-1}$ ampicillin or $25 \mu \mathrm{g} \mathrm{ml}^{-1}$ kanamycin (Table S1) and grown at $37^{\circ} \mathrm{C}$ until an $\mathrm{OD}_{600}$ of 0.6 was reached. Expression of recombinant protein was induced with $1 \mathrm{mM}$ isopropyl- $\beta$-D-thiogalactopyranoside (IPTG) overnight at $15^{\circ} \mathrm{C}$. Cells were harvested and resuspended in $5 \mathrm{ml}$ of buffer $\mathrm{A}(50 \mathrm{mM}$ sodium phosphate, $0.3 \mathrm{M} \mathrm{NaCl}$, pH 8.0 and $25 \mu \mathrm{M}$ pyridoxal phosphate (PLP)) containing 5 $\mathrm{mM}$ imidazole and disintegrated by sonication. Soluble fractions were recovered by centrifugation at $16,000 \times \mathrm{g}$ for $30 \mathrm{~min}$ at $4^{\circ} \mathrm{C}$. Proteins were affinity purified by applying the soluble fraction to a 13-ml nickel-nitrilotriacetic column (bioCAD 700E workstation) pre-equilibrated with buffer A. The column was washed with $60 \mathrm{ml}$ and $30 \mathrm{ml}$ of buffer A containing $20 \mathrm{mM}$ and $60 \mathrm{mM}$ imidazole, respectively. The Histagged fusion proteins proteins were then eluted with $500 \mathrm{mM}$ imidazole in buffer A. The SAT-CS bi-enzyme complex was purified in a similar manner from BL21(DE3) co-expressing the N-terminal 6x His tagged SAT and the non-tagged L. major CS from separate plasmids (Table S1). The eluants of CS and CBS were dialysed against $50 \mathrm{mM}$ Tris-HCl, $\mathrm{pH} 7.9,25 \mu \mathrm{M}$ PLP overnight at $4^{\circ} \mathrm{C}$ whereas the eluants containing SAT and the SAT-CS bi-enzyme complex were dialysed against $50 \mathrm{mM}$ Tris-HCl, $\mathrm{pH}$ 7.9 at $4{ }^{\circ} \mathrm{C}$ overnight. All proteins were stored at $4^{\circ} \mathrm{C}$ and their protein concentrations determined with a Bio-Rad protein assay kit (Bradford) using BSA as a standard. SAT and CS of Arabidopsis thaliania were expressed and purified as described previously [14] using the same expression constructs (gifts from Prof R. Hell, Germany) and used as positive controls in this study. Site directed mutagenesis of L. major CS and Arbidopsis CS was performed with the primer and plasmid combinations specified in 
Table S1 using the QuickChange ${ }^{\mathrm{TM}}$ site-directed mutagenesis kit (Stratagene) according to manufacturer's instructions.

Enzymic activities of SAT, CS, and CBS - Cysteine synthase activity was determined at $37^{\circ} \mathrm{C}$ in a $500 \mu \mathrm{l}$ reaction containing $200 \mathrm{mM}$ potassium phosphate, 1 $\mathrm{mg} \mathrm{ml}^{-1} \mathrm{BSA}, 1 \mathrm{mM}$ EDTA, $0.2 \mathrm{mM}$ PLP, $30 \mathrm{mM}$ OAS, $3 \mathrm{mM} \mathrm{Na}_{2} \mathrm{~S}$ and $15 \mathrm{ng}$ CS or $0.1 \mu \mathrm{g}$ CBS as appropriate. The enzyme and substrate were pre-incubated for $5 \mathrm{~min}$ at $37^{\circ} \mathrm{C}$ before starting the reaction by addition of sodium sulfide. Samples were taken after 5,10 and $15 \mathrm{~min}$ at $37^{\circ} \mathrm{C}$ and the cysteine concentration was quantified using the method of [15]. The first step of this procedure, in which the sample is diluted 5-fold in $0.4 \mathrm{M}$ nitrous acid, effectively stops the reaction. Serine sulfhydrylase (SS) activity of CS, in which serine combines with sulphide to form cysteine, was determined in the same way as described for the CS assay above, except that $50 \mathrm{mM}$ serine was used instead of OAS. To determine whether sulphide produced by the action of mercaptopyruvate sulfurtransferase (MST) on $\beta$ mercatopyruvate (MP) could be utilized by CS for cysteine biosynthesis, assays were run for $5 \mathrm{~min}$ with varying concentrations of MP (ranging from 0-10 $\mathrm{mM}$ ) and excess $\beta$-mercaptoethanol $(5 \mathrm{mM})$ and $0.5 \mu \mathrm{g}$ MST to generate sulfide that could subsequently condense with OAS. $30 \mathrm{mM}$ OAS and $0.5 \mu \mathrm{g} \mathrm{CS}$ were added to the reaction after the preincubation and incubated for a further $5 \mathrm{~min}$; the amount of cysteine produced was then quantified as described above.

Cystathionine production from homocysteine and serine (CBS activity) was determined in a $100 \mu \mathrm{l}$ reaction containing $50 \mathrm{mM}$ Tris- $\mathrm{HCl}, \mathrm{pH} 7.3,10 \mathrm{mM}$ serine, $10 \mathrm{mM}$ homocysteine, $0.25 \mathrm{mM}$ PLP and $0.1 \mu \mathrm{g}$ enzyme. All components were equilibrated to $37^{\circ} \mathrm{C}$ and the reaction initiated with enzyme. After 2-5 min incubation at $37^{\circ} \mathrm{C}$, the reaction was stopped with $50 \mu \mathrm{l} 20 \%(\mathrm{w} / \mathrm{v}) \mathrm{TCA}$ and incubated on ice for $10 \mathrm{~min}$. The mixture was centrifuged for $5 \mathrm{~min}$ at $16,000 \mathrm{x}$ g and the supernatant used for cystathionine analysis as described by [5]. The amount of cystathionine formed was determined by adding $1 \mathrm{ml}$ of ninhydrin reagent $\left(10 \mathrm{~g} . \mathrm{L}^{-1}\right.$ in glacial phosphoric acid) to $130 \mu$ lassay supernatant, boiling ( $5 \mathrm{~min}$ ), cooling on ice ( $2 \mathrm{~min}$ ) and incubating for $20 \mathrm{~min}$ at room temperature for colour development. The absorbance was measured at $455 \mathrm{~nm}$. A standard curve was prepared with cystathionine (0-500 nmol) dissolved in ninhydrin reagent and treated as described above to quantify the amount of cystathionine formed. Cystathionine production from homocysteine and cysteine (homocysteine sulfhydrylase activity) was determined in a $100 \mu \mathrm{l}$ reaction containing $50 \mathrm{mM}$ Tris- $\mathrm{HCl}, \mathrm{pH} 7.3,0.3 \mathrm{mM}$ homocysteine, $5 \mathrm{mM}$ cysteine, $0.25 \mathrm{mM}$ PLP and $0.3 \mu \mathrm{g}$ enzyme. Again, all components were equilibrated at $37^{\circ} \mathrm{C}$ and the reaction initiated with enzyme. The amount of cystathionine formed was quantified as described above.

Sulfide production in the cysteine desulfhydration reaction, in which cysteine combines with $\beta$-mercaptoethanol to form S-2-hydroxyethylcysteine and hydrogen sulfide [16], was monitored by trapping the sulfide with lead acetate [12]. The $1 \mathrm{ml}$ reaction mixture contained $50 \mathrm{mM}$ Tris- $\mathrm{HCl}, \mathrm{pH} 8.0,10 \mathrm{mM}$ cysteine, $20 \mathrm{mM} \beta$ mercaptoethanol, $0.1 \mathrm{mM}$ PLP, $0.33 \mathrm{mM}$ lead acetate and $300 \mathrm{ng}$ CBS or CS (to start the reaction). The hydrogen sulfide released during incubation at $37^{\circ} \mathrm{C}$ was determined by monitoring the production of lead sulphide through its absorbance at 
$360 \mathrm{~nm}$. Homocysteine desulfurase activity was measured similarly except that $5 \mathrm{mM}$ of homocysteine was used instead of cysteine.

SAT catalyzes the formation of O-acetylserine and CoA from serine and acetyl-CoA. A 5,5'-dithiobis-(2-nitrobenzoic acid) (DTNB) assay was used to quantify CoA production as described by [17]. In this, DTNB reacts with the sulfhydryl compound CoA to form $\mathrm{TNB}^{-}$, which has an extinction coefficient at $412 \mathrm{~nm}$ of 13600 . The assay was carried out at $37^{\circ} \mathrm{C}$ in $100 \mathrm{mM}$ Tris- $\mathrm{HCl}, \mathrm{pH} 8.0$, with $0.1 \mathrm{mM}$ acetyl CoA, $1 \mathrm{mM}$ serine, $0.4 \mathrm{mg} \mathrm{ml}^{-1} \mathrm{DTNB}$ and 5-50 $\mu \mathrm{g}$ enzyme. The reaction was initiated by the addition of serine and the absorbance at $412 \mathrm{~nm}$ was monitored continuously at $37^{\circ} \mathrm{C}$ for $5-10 \mathrm{~min}$.

Kinetic parameters were calculated using Grafit 5 (Erithacus Software Ltd) software.

Western blot analysis and SDS-PAGE - Rabbit polyclonal $\alpha$-CS and $\alpha$-CBS antisera were raised against recombinant proteins of each of SAT, CS and CBS of $L$. major by the Scottish Antibody Production Unit (Carluke, UK), using standard protocols. Parasite lysates were produced by resuspension of parasite pellets in lysis buffer $(0.25 \mathrm{M}$ sucrose, $0.25 \%$ (v/v) Triton X-100, $10 \mathrm{mM}$ EDTA, $10 \mu \mathrm{M}$ E-64, 2 $\mathrm{mM}$ 1,10-phenanthroline, $4 \mu \mathrm{M}$ pepstatin $\mathrm{A}$, and $1 \mathrm{mM}$ phenylmethylsulfonyl floride). Lysates were centrifuged at $13,000 \mathrm{x}$ g for $30 \mathrm{~min}$ at $4^{\circ} \mathrm{C}$, and an aliquot of the resulting supernatant $(8 \mu \mathrm{g}$ protein) were subjected to Western blot analysis as described previously [12]. The polyclonal immune rabbit antisera against SAT, CS, CBS, MST and thiol-dependent reductase 1 (TDR1) were diluted 1:2000 (v/v), $1: 5000(\mathrm{v} / \mathrm{v}) ; 1: 2000(\mathrm{v} / \mathrm{v}) ; 1: 2000(\mathrm{v} / \mathrm{v})$ and 1:5000(v/v), respectively, in Tris-buffered saline containing $1 \%(\mathrm{w} / \mathrm{v})$ low fat dried milk and $0.1 \%(\mathrm{v} / \mathrm{v})$ Tween 20 . Monoclonal immune mouse serum recognising the His-tag of the proteins was used at 1:5000 (v/v) in the same buffer. Bound antibody was detected using horseradish peroxidasecoupled secondary $\alpha$-mouse (1:5000) and $\alpha$-rabbit (1:5000) antibodies (Scottish Antibody Production Unit) and ECL Western blotting detection reagents (Pierce Ltd) according to the manufacturer's recommendations. The antisera against MST and TDR1, used as loading controls, have been described previously [12,18]. ImageJ (http://rsb.info.nih.gov/ij/index.html) was used to quantify the Western blot signals in order to make comparisons.

Cysteine transport assay - Transport of $\left[{ }^{35} \mathrm{~S}\right]$-L-cysteine (American radiochemicals) into L. major promastigotes was performed using the oil stop technique as described previously [19]. Briefly, promastigotes were harvested and washed with CBSS pH $7.4\left(33 \mathrm{mM}\right.$ HEPES, $98 \mathrm{mM} \mathrm{NaCl}, 4.6 \mathrm{mM} \mathrm{KCl}, 0.3 \mathrm{mM} \mathrm{CaCl}_{2}, 0.07 \mathrm{mM} \mathrm{MgSO}_{4}$, $5.8 \mathrm{mM} \mathrm{NaH}_{2} \mathrm{PO}_{4}, 0.3 \mathrm{mM} \mathrm{MgCl}_{2}$ and $14 \mathrm{mM}$ D-glucose) and resuspended in CBSS

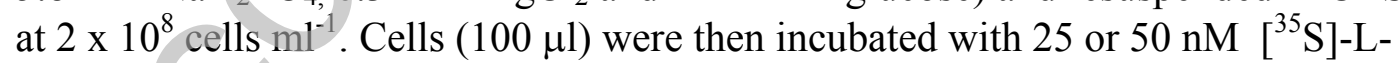
cysteine together with non-radioactive cysteine in a microcentrifuge tube containing $200 \mu \mathrm{loil}(7: 1 \mathrm{v} / \mathrm{v}]$ dibutyl-phthalate/mineral oil; $\left.d=1.018 \mathrm{~g} \cdot \mathrm{ml}^{-1}\right)$ for a period at $25^{\circ} \mathrm{C}$, as indicated in Results. Incubations were terminated by centrifugation of cells through the oil at $16,000 \mathrm{x} g$ for $1 \mathrm{~min}$. This separates the radiolabelled cells from extracellular radioactivity. The tubes were frozen in liquid nitrogen and the tips containing the cell pellets cut off, whereupon the contents were solubilised in $2 \%$ (w/v) SDS for $30 \mathrm{~min}$. Three $\mathrm{ml}$ of scintillation fluid (Optiphase HiSafe III; PerkinElmer) were added and left overnight at room temperature. Radioactivity in the cell pellet was then determined using a 1450 MicroBeta Trilax liquid scintillation counter. 
The zero uptake background was determined with cells prepared as described above, but with all operations at $0^{\circ} \mathrm{C}$ and with immediate termination by centrifugation. The assays were carried out using triplicates and transport values were determined by subtraction of the zero uptake background values. Kinetic parameters were calculated using Grafit 5 (Erithacus Software Ltd) software.

Analysis of intracellular thiols levels using HPLC - L. major promastigotes were harvested from late $\log$ phase cultures using $2500 \mathrm{x}$ g for $10 \mathrm{~min}$ and resuspended at $2.5 \times 10^{7}$ in $50 \mu$ of $40 \mathrm{mM} \mathrm{N}$-[2-hydroxyethyl]-piperazine-N'[3-propanesulphonic acid], $4 \mathrm{mM}$ diethylenetriamine pentaacetic acid, $\mathrm{pH} 8.0$, containing $0.7 \mathrm{mM}$ tris(2carboxyethyl)phosphine and incubated at room temperature for $45 \mathrm{~min}$.

Monobromobimane was added to give a final concentration of $1 \mathrm{mM}$ and the mixture was heated for $3 \mathrm{~min}$ at $70^{\circ} \mathrm{C}$. Extracts were deproteinised by addition of an equal volume of $4 \mathrm{M}$ methanesulphonic acid, $\mathrm{pH} 1.6$, and incubated on ice for $30 \mathrm{~min}$. Proteins were removed by centrigugation at $16,000 \times \mathrm{g}$ for $7 \mathrm{~min}$ at $4^{\circ} \mathrm{C}$ and the resultant supernatants were analysed by HPLC (using a UltiMate HPLC syetem [Dionex] and a GEMINI C18 column [Phenomenex]). The mobile phase consisted of two solvents: solvent A, $0.25 \%$ acetic acid; solvent B, 100\% acetonitrile. Metabolites were separated at a flow rate of $0.55 \mathrm{ml} \mathrm{min}^{-1}$ by application of the following gradient ( $\%$ of solvent B): 0 min, $0 \%$; $10 \mathrm{~min}, 0 \%$; $40 \mathrm{~min}, 8 \% ; 100 \mathrm{~min}, 15 \% ; 110 \mathrm{~min}, 50 \%$; $111 \mathrm{~min}, 0 \% ; 121 \mathrm{~min}, 0 \%$. Thiols were detected using a fluorescence detector (excitation, $365 \mathrm{~nm}$; emission, $480 \mathrm{~nm}$ ). Glutathionine, cysteine and trypanothionine were identified by comparison of their retention times with those of their respective standards. A standard curve for quantitation was achieved by integration of peak areas of known quantities of thiols, and experimental peak areas were compared with this curve to determine nmol of thiol $\left(10^{8} \text { cells }\right)^{-1}$. Total thiols were calculated as the sum of cysteine, glutathione and $2 \mathrm{x}$ trypanothione concentrations. Differences were analyzed using parametric Student's 2-tailed $t$ tests. The data presented are from three independent experiments.

\section{Results}

\section{Identification of genes encoding enzymes of cysteine biosynthesis in $L$. major} We identified Leishmania genes likely to encode enzymes involved in cysteine biosynthesis by searching the Leishmania genome databases (http://www.ebi.ac.uk/Tools/blast2/parasites.html) using protein sequences from plants, bacteria, yeast and parasitic protozoa orthologues as the queries. The L. major sequences identified were then back-searched against the SWISSPROT database to confirm gene identity. These analyses suggest that $L$. major, L. infantum and $L$. braziliensis all have enzymes comprising two cysteine biosynthetic routes, the de novo biosynthesis and the RTS pathways (Table 1, Figure 1). The L. major genome contains single copy genes, validated by Southern blot analysis (data not shown), for CBS (LmjCBS; LmjF17.0250) and CGL (LmjCGL; LmjF35.3230) of the RTS pathway, and CS (LmjCS; LmjF36.3590) and SAT (LmjSAT; LmjF34.2850) of the de novo biosynthesis pathway. Each of the four predicted enzymes has the key residues and motifs reported to be required for activity, as detailed below. In addition, L. major encodes cystathionine $\gamma$-synthase (LmjCGS; LmjF14.0460) and cystathionine $\beta$-lyase

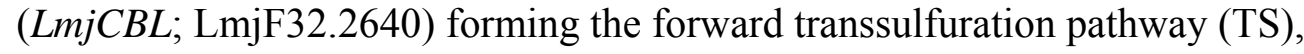
implying that the parasites also can convert cysteine into methionine. A similar search of the T. cruzi genome (www.geneDB.org), a related parasite, also identified 
orthologues of both biosynthetic pathways, although there appear multiple copies of all the genes (Table 1). The T. brucei genome (www.geneDB.org), on the other hand, contains single copies of genes encoding enzymes of the RTS pathway but lacks genes encoding the proteins of the cysteine de novo biosynthetic and TS pathways. LmjSAT encodes a protein of 411 amino acids $(45.5 \mathrm{kDa})$ with significant identities to the multiple SATs of other protozoa - T. cruzi (38.4-39.1\%) and E. histolytica (21.7$30.4 \%$ ) (Figure S1A). The hexapeptide structural domain required for acyltransferases activity (residues 274-380; L. major numbering) and the $\beta$-cluster (residues 277-364) that interacts with CS to form the bi-enzyme complex (Figure S1A) [20,21] are also conserved. The residues likely to be involved in acetyl CoA binding comprise Cys ${ }^{376}$, $\mathrm{Pro}^{383}, \mathrm{Gln}^{391}$ and $\mathrm{Ser}^{393}$, respectively, in contrast to Arabidopsis where they are $\mathrm{Ser}^{263}, \mathrm{Pro}^{270}, \mathrm{Gly}^{277}$ and Pro ${ }^{279}[22,23]$.

LmjCS encodes a protein of 342 amino acids $(35.5 \mathrm{kDa})$ with high sequence identities with CSs of other protozoa $-72 \%$ for T. cruzi, $42 \%$ for E. histolytica and $34-38 \%$ for T. vaginalis (Figure S1B). LmjCS has the four lysine residues (Lys ${ }^{40}$, Lys $^{52}$, Lys ${ }^{67}$ and Lys ${ }^{199}$ ) required for binding the pyridoxal phosphate (PLP) cofactor and thought to be essential for sulfhydrylase activity [24]. All CS enzymes have a similar structure and catalytic mechanism but show differences in substrate specificity determined in part by the structure of the $\beta 8$ - $\beta 9$ loop that lines the entry to the active site [10]. The short loop found in the type A isoforms of bacterial and plant CSs [25] severely restricts access to the active site and these enzymes have a strict specificity for OAS and sulfide. The type B CS isoforms of bacteria [25], thermophiles [26] and Trichomonas [11] have an extended loop containing a conserved charged residue that allows the use of larger, negatively charged molecules such as $O$-phosphoserine and thiosulfate as substrates. Sequence comparison shows that LmjCS has the short $\beta 8$ $\beta 9$ loop similar to bacterial type A CS isoforms and thus we predicted that it has a substrate preference for sulfide and OAS. LmjCS also contains the residues $\left(\mathrm{K}^{222}\right.$, $\mathrm{H}^{226}$ and $\mathrm{K}^{227}$ ) implicated for plant [27] and bacterial type A [28] CSs in binding to SAT which, together with the presence of the $\beta$-cluster residues in LmjSAT, suggested that the two are likely to interact to form a LmjSAT-LmjCS bi-enzyme complex; the equivalent in other organisms plays roles in activating SAT and/or regulating CS activity $[27,29]$. These residues are absent from type B CS isoforms that do not form a complex with SAT.

CBS is also a PLP-dependent enzyme, evolutionarily related to CS and in most cases with some CS activity [14]. LmjCBS encodes a protein of 359 amino acids (39.2 kDa) which has three ( $\mathrm{Lys}^{42}, \mathrm{Lys}^{53}$ and $\mathrm{Lys}^{202}$ ) of the four lysine residues reported to be required for activity of other CSs (Figure S1C) [30]. The fourth position in LmjCBS is, instead, Glu ${ }^{66}$. LmjCBS has relatively high amino acid sequence identity with LmjCS (31\%) and quite high identities with the region comprising the catalytic domain (residues 1-359; [5]) of CBSs from L. tarentolae (83\%), T. cruzi (56-66\%), H. sapiens (49\%) and S. cerevisiae (42\%). LmjCBS, however, differs from HsCBS in lacking the haem-binding motif and regulatory domain at the $\mathrm{N}$ - and $\mathrm{C}$-termini, respectively [31]. The haem-binding motif acts as a redox sensor [32], whereas the regulatory domain controls the tetrameric state of the protein and so CBS activity [32]. Interestingly, the Saccharomyces protein (ScCBS) also lacks the N-terminal haem-binding motif [33] but does possess the C-terminal regulatory domain $[8,34]$ whereas TcCBS lacks the $\mathrm{C}$-terminal regulatory domain but has an $\mathrm{N}$-terminal extension (Figure S1C) - although this does not bind haem [5]. LmjCBS, TcCBS and ScCBS all also lack the oxidoreductase (CysXXCys) motif of HsCBS [35]. 
LmjCGL encodes a protein of 552 amino acids $(60.6 \mathrm{kDa})$ and has the PLP-binding moiety (between positions 197-202) and the reactive lysine (Lys ${ }^{199} ;$ L. major numbering) required for activity (Figure S1D) [36]. LmjCGL's identities with other CGLs are Bacillus subtilus (38\%), S. cerevisiae (35\%), H. sapiens (34\%), T. brucei (72\%) and T. cruzi (80\%).

\section{CS of $L$. major catalyzes the synthesis of cysteine from $O$-acetylserine}

Soluble recombinant LmjCS (rLmjCS) was produced in large quantities $\left(\sim 25 \mathrm{mg} \cdot \mathrm{L}^{-1}\right)$ using the pET21a+ expression plasmid in BL21(DE3) E. coli and purified to apparent homogeneity for analysis (Figure S2). rLmjCS activity was optimal at $\mathrm{pH} 8.0$ and $37^{\circ} \mathrm{C}$ and was stable for several weeks without any appreciable loss of activity when stored at $4^{\circ} \mathrm{C}$ (data not shown). The apparent $\mathrm{K}_{\mathrm{cat}} \mathrm{S}$ of $\mathrm{rLmjCS}$ using $\mathrm{O}$-acetylserine (OAS) and sodium sulfide were $2047 \mathrm{sec}^{-1}$ and $2669 \mathrm{sec}^{-1}$ for OAS and sulphide, respectively (Table 2$)$. The $K_{m}$ for sulfide was low $(0.13 \mathrm{mM})$. No activity was detected between OAS and methanethiol or sodium thiosulfate (the detection limit being $0.6 \mu \mathrm{mol} \mathrm{min}{ }^{-1} \mathrm{mg}$ protein $\left.{ }^{-1}\right)$. rLmjCS was unreactive towards Oacetylhomoserine $(50 \mathrm{mM}), \mathrm{O}$-succinylhomoserine $(50 \mathrm{mM})$, O-phosphoserine (100 $\mathrm{mM}$ ) or serine $(50 \mathrm{mM})$ and sodium sulfide (the detection limit being $0.2 \mu \mathrm{mol} \mathrm{min} \mathrm{m}^{-1}$ $\mathrm{mg}$ protein $\left.^{-1}\right)$. rLmjCS had no detectable CBS activity that forms cystathionine from serine and homocysteine (the detection limit being $0.4 \mu \mathrm{mol} \mathrm{min}{ }^{-1} \mathrm{mg} \mathrm{protein}^{-1}$ ). rLmjCS also has cysteine desulfurase activity hydrolysing cysteine to yield sulfide, but only in the presence of $\beta$-mercaptoethanol, with a $\mathrm{K}_{\mathrm{cat}} \mathrm{s}$ of $88.2 \mathrm{sec}^{-1}$ and $99.0 \mathrm{sec}^{-}$ ${ }^{1}$ for cysteine and $\beta$-mercaptoethanol, respectively (Table 2 ). It has been proposed that this desulfurase activity has a reaction mechanism similar to the sulfhydrylase reaction [16]. In this, cysteine binds to the enzyme and sulfide by $\beta$-elimination to form the $\alpha$-aminoacrylate intermediate, $\beta$-mercaptoethanol then acts as the nucleophile in the second half-reaction to produce S-2-hydroethylcysteine. No desulfurase activity was detected with homocysteine $(50 \mathrm{mM})$ and $\beta$-mercaptoethanol or with cysteine or homocysteine and DTT (the detection limit being $0.2 \mu \mathrm{mol} \mathrm{min}{ }^{-1}$ $\mathrm{mg}_{\text {protein }^{-1}}$ ). $\mathrm{rLmjCS}$ was relatively insensitive to propargylglycine (PAG) and hydroxylamine, inhibitors of various PLP-dependent enzymes, with $1 \mathrm{mM}$ PAG and hydroxylamine inhibiting $r$ LmjCS sulfhydrylase activity only by $1 \%$ and $3 \%$, respectively. On the other hand, $1 \mathrm{mM}$ phenylhydrazine- $\mathrm{HCl}$ inhibited $\mathrm{CS}$ sulfhydrylase activity of $\mathrm{rLmjCS}$ by $36 \pm 0.2 \%$.

The source of the sulfide for the CS activity in Leishmania is unclear. Prokaryotes, plants and enteric protozoa assimilate inorganic sulphur into organic sulfur via the sulfate reduction pathway [6]. Our genome search suggests that this pathway is absent from L. major. Sulfide produced by the action of mercaptopyruvate sulfurtransferase (MST) on 3-mercaptopyruvate in a linked assay with rLmjCS gave a specific activity for CS of $1114 \pm 208 \mu \mathrm{mol} \mathrm{min}{ }^{-1} \mathrm{mg}$ protein ${ }^{-1}$, with the amount of cysteine produced roughly proportional to the amount of 3-mercaptopyruvate added up to $3 \mathrm{mM}$ (Figure 2).

\section{LmjCBS can synthesise both cystathionine and cysteine}

Recombinant LmjCBS (rLmjCBS) was produced at high quantities $\left(\sim 32 \mathrm{mg} . \mathrm{L}^{-1}\right)$ in $E$. coli and the enzyme purified to apparent homogeneity (Figure S2) showed multiple enzymatic activities. It was optimally active at $\mathrm{pH} 8.0$ and $37^{\circ} \mathrm{C}$ for all of its activities and was stable as purified for several weeks at $4^{\circ} \mathrm{C}$ without any appreciable loss of 
activity (data not shown). The CBS activity of rLmjCBS, utilising homocysteine and serine to generate cystathionine (Figure 3, reaction I), had $\mathrm{K}_{\mathrm{cat}} \mathrm{S}$ of $97.7 \mathrm{sec}^{-1}$ and 51.9 $\mathrm{sec}^{-1}$ for homocysteine and serine, respectively (Table 2). rLmjCBS was also capable of the $\beta$-replacement reaction, 'homocysteine sulfhydrylase' (Figure 3, reaction II), in which cysteine and homocysteine form cystathionine and hydrogen sulfide. The homocysteine sulfhydrylase reaction was only apparent at concentrations of cysteine $>0.1 \mathrm{mM}$, whereas homocysteine at concentrations greater than $0.3 \mathrm{mM}$ were inhibitory (Figure S3). Consequently, the kinetic parameters of LmjCBS for this reaction was carried out at homocysteine concentrations (up to $0.3 \mathrm{mM}$ ) that were not inhibitory and obeyed Michealis Menton kinetics (Figure S3). The resultant apparent $\mathrm{K}_{\mathrm{cat}} \mathrm{S}$ were $11.1 \mathrm{sec}^{-1}$ and $26.2 \mathrm{sec}^{-1}$ for homocysteine and cysteine, respectively (Table 2). rLmjCBS also showed remarkably high CS activity with OAS and sodium sulfide (Figure 3, reaction III), the apparent $\mathrm{K}_{\mathrm{cat}} \mathrm{s}$ being $2269 \mathrm{sec}^{-1}$ and $1516 \mathrm{sec}^{-1}$, respectively. However, the $\mathrm{K}_{\mathrm{m}}$ for sulphide was relatively high $(10.7 \mathrm{mM})$. rLmjCBS also had serine sulfhydrylase activity (cysteine being formed from serine and sodium sulfide; Figure 3, reaction IV) with $\mathrm{K}_{\mathrm{cat}} \mathrm{s}$ for serine and sodium sulfide being $14.2 \mathrm{sec}^{-1}$ and $14.1 \mathrm{sec}^{-1}$, respectively (Table 2). LmjCBS was also capable of the 'activated serine sulfydrase' activity, otherwise known as cysteine desulfurase (which generates S-hydroxyethylcysteine and hydrogen sulfide from cysteine and $\beta$-mercaptoethanol; Figure 3, reaction V), with $\mathrm{K}_{\mathrm{cat}} \mathrm{S}$ of $38.3 \mathrm{sec}^{-1}$ and $20.7 \mathrm{sec}^{-1}$ for cysteine and $\beta$ mercaptoethanol, respectively (Table 2). In the absence of $\beta$-mercaptoethanol there was a small activity, about $10 \%$ of that in the presence of $\beta$-mercaptoethanol; this is called reverse serine sulfydrase and forms serine and hydrogen sulfide from cysteine.

\section{LmjCS enhances the activity of LmjSAT in vitro}

LmjSAT was generated as recombinant enzyme (rLmjSAT) in soluble form using a $E$. coli system, but expression was low $\left(\sim 0.5 \mathrm{mg} . \mathrm{L}^{-1}\right)$. Using standard assay conditions described for other SATs, we failed to detect SAT activity towards serine and acetyl CoA with the purified rLmjSAT the detection limit being $0.2 \mu \mathrm{mol} \mathrm{min}^{-1} \mathrm{mg}_{\text {protein }}$ ${ }^{1}$ ) whereas recombinant SAT of Arabidopsis, used as a positive control, showed activity of $2.8 \mu \mathrm{mol} \mathrm{min} \mathrm{mg}^{-1} \mathrm{mg}$ protein ${ }^{-1}$. This finding for rLmjSAT was surprising and contrasted to that reported for T. cruzi SAT (TcSAT) [5], although LmjSAT has only $17 \%$ identity to TcSAT. We hypothesised that LmjSAT needs to be activated by LmjCS. When LmjSAT, tagged at the N-terminus with a 6x His-tag, was coexpressed with LmjCS (without a His-tag) in E. coli and the resultant LmjSAT then affinity-purified (see below) and assayed, SAT activity was detected (specific activity of 90 nmole $\mathrm{min}^{-1} \mathrm{mg}$ protein ${ }^{-1}$; a rate 4-fold higher than background under the experimental conditions used) at a rate comparable to that reported for TcSAT [5]. No kinetic analysis was possible due to low availability of rLmjSAT. These data suggested that LmjCS stabilises and/or enhances LmjSAT activity, perhaps through formation of a complex.

\section{LmjSAT interacts with LmjCS to form a complex in vitro}

The formation of a SAT-CS complex has been described previously for plant proteins $[14,37]$. We investigated whether the Leishmania proteins do likewise by His-tagging rLmjSAT at its N-terminus (to give His-LmjSAT) and co-expressing in E. coli with LmjCS (devoid of any tag). Purification was then conducted using affinity chromatography targeting the His-tag. The expectation was that if LmjCS interacts with His-LmjSAT, the complex should be retained on the column; elution could then be achieved with either OAS (10 mM), which would remove CS from the complex, or 
imidazole $(500 \mathrm{mM})$, which would remove the whole complex by interfering with the His-binding. This procedure has been validated for plant enzymes [14,29,37]. SDSPAGE analysis of the eluates in our experiments revealed that rLmjCS and rLmjSAT were indeed retained on the column and eluted by $500 \mathrm{mM}$ imidazole (Figure 4A; Figure 4Bi, lane 1) similarly to a positive control involving the Arabidopsis SATLmjCS complex (Figure 4Bii, lane 1). Initial elution of the column with wash buffer (50 mM Tris $\mathrm{HCl}, \mathrm{pH} 8.8,300 \mathrm{mM} \mathrm{NaCl}, 80 \mathrm{mM}$ imidazole) containing $10 \mathrm{mM}$ OAS resulted in just rLmjCS being recovered in the eluate (Figure 4Bi, lane 3). rLmjSAT was subsequently eluted by washing the column with elution buffer containing 500 $\mathrm{mM}$ imidazole (Figure 4Bi, lane 4). rLmjSAT expressed alone in E. coli and purified under similar conditions is shown in Figure 4Bi, lane 2.

With A. thaliana CS (designated AtOASTL or AtCS), the positively charged residues $\mathrm{K}^{217}, \mathrm{H}^{221}$ and $\mathrm{K}^{222}$ located in loops $\beta 8-\beta 9$ govern its interaction with $\mathrm{SAT}$, and removal of the residues through site-directed mutagenesis disrupts complex formation [27]. Alignment of LmjCS with the AtOASTL revealed that the residues are conserved in LmjCS $\left(\mathrm{K}^{222}, \mathrm{H}^{226}\right.$ and $\mathrm{K}^{227}$ ) (Figure 4Ci). Thus we generated two mutants (designated LmjCS(K222A) and LmjCS(H226A/K227A) and analysed them for interactions with LmjSAT. As predicted, LmjCS(K222A) and LmjCS (H226A/K227A) failed to interact with the native LmjSAT (Figure 4Cii, lanes 2 and 3) while the native LmjCS bound well (Figure 4Cii, lane 1). Further, our interaction assay also showed that rLmjSAT can interact with CS from Arabidopsis (AtOASTL) to form a rLmjSAT/AtOASTL complex (Figure 4Cii, lane 4). As expected, a AtOASTL mutant designated AtOASTL(K217A) showed no interaction with rLmjSAT (Figure 4Cii, lane 5). The CS of T. vaginalis (TvCS) also did not interact with rLmjSAT (Figure 4Cii, lane 6), as expected as it is a type B CS and lacks the key residues (Figure 4Ci and [11]). We also showed that SAT from A. thaliana interacts with rLmjCS in a similar manner, while LmjCS(K222A) and LmjCS(H226A/K227A) showed much less binding to the Arabidopsis SAT (Figure 4Bii).

\section{Methionine and not cysteine is essential for the growth of $L$. major promastigotes}

It has been reported that cysteine is an essential growth factor for T. brucei [4]. We now know that this protozoon encodes genes for only the RTS pathway for cysteine generation, which may be inadequate to satisfy its cysteine requirement. It seemed likely, however, that the existence of the two cysteine biosynthetic pathways in Leishmania would make it insensitive to the absence of an exogenous source of cysteine. This hypothesis was tested using L. major wild type promastigotes cultured in a semi-defined medium depleted of serine, cysteine and methionine (designated sulphur-depleted medium: SDM) and supplemented with $20 \%(\mathrm{v} / \mathrm{v})$ dialysed foetal calf serum (dFCS). Cultures were initiated with promastigotes at $2.5 \times 10^{5}$ cells ml $^{-1}$ and growth monitored over 5 days. Promastigotes in the control experiments were maintained in normal medium supplemented with $10 \%(\mathrm{v} / \mathrm{v})$ normal FCS. As expected, promastigotes maintained in normal medium grew well but growth was retarded in promastigotes maintained in SDM although they remained motile and viable (Figure 5). The addition of exogenous cysteine or methionine at $300 \mu \mathrm{M}$ had no significant effect on the growth of L. major promastigotes (Figure 5A), nor did addition of thiosulfate. Exogenous serine (at $300 \mu \mathrm{M}$ ), however, resulted in enhanced growth (Figure 5A). These data are consistent with the absence of genes encoding proteins involved in the de novo synthesis of serine in this protozoon [6] and thus with 
exogenous serine being essential [38]. Thus serine was added to SDM (this medium being designated SSDM) and a reanalysis of the importance of the other additions was carried out (Figure 5B). Of all the substances added, only methionine restored promastigote growth to that of the control cells maintained in normal medium (Figure 5B). Addition of cysteine failed to significantly stimulate growth of promastigotes maintained in SSDM $(\mathrm{P}>0.5)$. Higher concentrations of cysteine $(>300 \mu \mathrm{M})$ retarded promastigote growth; indeed death ensued within $24 \mathrm{~h}$ at concentrations of $10 \mathrm{mM}$ (data not shown). In total, these data suggest that L. major differs from T. brucei in that methionine and not cysteine is markedly beneficial for growth.

Next, we investigated the effect of the exogenous sources of organic sulfur on the thiol levels in L. major promastigotes cultured in RPMI (lacking cysteine and methionine) supplemented with cysteine or methionine by using HPLC (Figure 5C). Growth of Leishmania promastigotes in RPMI and SSDM was equivalent under all conditions tested (data not shown). Promastigotes cultured in normal medium were used as the controls (Figure 5C, lane 4). Compared with the control promastigotes, the total thiol levels were reduced 3.8-fold $(\mathrm{P}<0.005)$ in promastigotes cultured in RPMI and to $59 \%(\mathrm{P}<0.05)$ in RPMI supplemented with cysteine. In contrast, the total thiol levels in promastigotes cultured in RPMI supplemented with methionine were slightly higher $(1.4$-fold, $\mathrm{P}<0.05)$ than those in the control promastigotes in normal medium (Figure 5Ci). The decreased thiol levels in L. major promastigotes cultured in RPMI or RPMI supplemented with cysteine correlated well with the reduced growth observed (Figure 5B). Analysis of the levels of cysteine, glutathione and trypanothione revealed detailed differences (Figure 5Cii). The thiol concentrations in control cells are similar to those previously reported [39]. Compared with promastigotes grown in normal medium, cells grown in RPMI showed reduced levels of all thiols. Cells grown in RPMI with methionine had similar levels of cysteine and glutathione to the control but trypanothione levels were increased 2.4-fold $(\mathrm{P}<0.005)$. Cells grown in RPMI supplemented with cysteine showed increased levels of glutathione (2.3-fold, $\mathrm{P}<0.05)$ and trypanothione $(2.8$-fold, $\mathrm{P}<0.05)$ compared with promastigotes cultured in just RPMI, which apparently accounted for the increase in total thiol content $(2.2$-fold higher, $\mathrm{P}<0.05)$. The levels of glutathione and trypanothione in RPMI supplemented with cysteine were relatively similar to the levels in the control cells grown in normal medium. Importantly, however, addition of exogenous cysteine did not result in an increase in the intracellular level of cysteine, which was only $12 \%$ of the level seen in the control cells.

Promastigotes maintained in SSDM had increased levels of LmjCS, as judged by Western blot analysis (Figure 5Di, lane 1). This increase was validated by densitometric analysis using Image J software (Figure 5Dii). LmjCS and LmjCBS in promastigotes growing in SSDM with cysteine (Figure 5C, lane 3) or methionine (Figure 5C, lane 4) was relatively similar to the level in wild type cells in normal nutrient-rich medium (Figure 5C, lane 2). These data suggest that enzymes from cysteine biosynthetic pathways are present and presumably functional in promastigotes, and that the level of CS can be adjusted in attempts to accommodate variations in the availability of exogenous amino acids.

\section{Transport of $\left[{ }^{35} \mathrm{~S}\right]-\mathrm{L}-\mathrm{cysteine}$ into $L$. major promastigotes}

Having established that an exogenous source of cysteine does not stimulate growth of L. major promastigotes and has little effect on the intracellular cysteine levels, 
whereas exogenous methionine does, we examined the ability of promastigotes to utilize an exogenouse source of cysteine. Leishmania is known to take up exogenous methionine [40]. A transport assay with $\left[{ }^{35} \mathrm{~S}\right]-\mathrm{L}$-cysteine showed that L. major promastigotes can take up cysteine and that the transport was linear for at least $5 \mathrm{~min}$ (Figure 6A, insert) but declined markedly by $25 \mathrm{~min}$ (Figure 6A). $\left[{ }^{35} \mathrm{~S}\right]$-L-cysteine transport measured as a function of different concentrations of extracellular cysteine showed a typical Michaelis-Menton hyperbolic curve and displayed an apparent $\mathrm{K}_{\mathrm{m}}$ of $229 \pm 39 \mu \mathrm{M}(\mathrm{n}=3)$ and $\mathrm{V}_{\max }$ of $16.9 \pm 1.3 \mathrm{pmol} \mathrm{min}^{-1}\left(10^{7} \text { cells }\right)^{-1}$ (Figure $\left.6 \mathrm{~B}\right)$. The transport of cysteine was investigated using a range of non-radioactive cysteine, which showed that as expected cysteine inhibited $\left[{ }^{35} \mathrm{~S}\right]-\mathrm{L}$-cysteine transport into promastigotes (Figure S4). These results show that cysteine can be transported into $L$. major promastigotes, at only at a low rate.

\section{Discussion}

This study has shown that L. major possesses enzymes of each of two pathways for cysteine synthesis - the de novo biosynthesis pathway comprising serine acetyltransferase (SAT) and cysteine synthase (CS) and the reverse transsulfuration (RTS) pathway comprising cystathionine $\beta$-synthase (CBS) and cystathionine $\gamma$-lyase (CGL). Biochemical analysis of the recombinant CS has shown that the enzyme has high activity with O-acetylserine (OAS) and sulfide as substrates (Table 2) but is unable to utilise thiosulfate and phosphoserine. This substrate preference suggest that the Leishmania enzyme is similar to type A CSs of bacteria and has a $\beta 8$ - $\beta 9$ surface loop that restricts access to the active site pocket. The protein structure predicted from the gene sequence is in agreement with this (Figure S1B). The type B CSs of bacteria [25] and the CSs of A. pernix [26] and T. vaginalis [11] all have a different structure in this region, centred around a conserved positively charged residue that confers greater flexibility and allows the use of larger, negatively charged substrates (Figure S1B).

It has been shown that type A CSs of bacteria and Arabidopsis CS form bi-enzyme complexes with SAT, that are dissociated by OAS in the absence of sulfide $[14,29,41]$. The C-terminal residues of SAT bind to sequence motifs in the $\beta 8-\beta 9$ surface loop and the substrate binding-loop in the active-site cleft; this completely fills the active site of CS and results in inhibition of its activity [27,29,42]. The substrate binding loop is conserved in all CS enzymes whereas the SAT-binding motif in the $\beta 8-\beta 9$ loop is not found in the type B CSs of bacteria, which do not form a complex with SAT. Consistent with this, the CS enzymes of organisms that do not contain genes for SAT, notably A. pernix [42] and T. vaginalis [11], also lack this binding motif in the $\beta 8-\beta 9$ loop. The gene sequences of the CSs of Leishmania show that the proteins do contain this SAT-binding motif and the consequent prediction that the enzyme will form a complex with SAT was confirmed in this study (Figure 4). Mutagenesis of LmjCS also indicated that residues equivalent to those of AtOASTL are involved in the binding to SAT (Figure 4).

The function of the CS-SAT bi-enzyme complex in Leishmania remains to be proven, but based on the findings for bacteria and plants $[14,17,37,44]$ it is likely to have a regulatory role. The two enzymes show opposite responses to being part of the complex: SAT is inactivated or less active when released from the complex, whereas CS is completely inactive when in complex with SAT but highly active as a free 
enzyme $[14,29,45]$. The data for Leishmania SAT is consistent with this, as SAT activity could only be detected when co-expressed with CS, but how this plays a part in cysteine homeostasis requires additional study.

The source of sulfide for cysteine synthesis in L. major is unclear. Plants, bacteria, and Entamoeba assimilate inorganic sulphur via the sulfide reduction pathway, but genes encoding enzymes of this pathway appear to be absent from the L. major genome. We postulated that the sulfide required by CS may be provided by the action of mercaptopyruvate sulfurtransferase (MST) on 3-mercaptopyruvate. This enzyme has previously been implicated in sulfide production and antioxidant defence [12] and we have now shown that LmjCS can indeed use sulfide emanating from the activity of MST to form cysteine at a rate similar to that when sulfide itself is provided (Figure 2). Such activity in vitro, however, does not mean that this is the in vivo source; this suggestion needs to be validated by genetic studies. An alternative is that sulfide could potentially be provided exogenously for the parasite in the parasitophorous vacuole, and/or the insect gut, although evidence that this is so is currently lacking.

This study has also established that L. major CBS is clearly different from mammalian CBSs; it lacks the $\mathrm{N}$-terminal haem-binding motif and the $\mathrm{C}$-terminal regulatory domain present in mammalian CBSs, moreover it is capable of using a wide variety of substrates (Table 2). LmjCBS does, unsurprisingly, possess CBS activity - to produce cystathionine (Figure 3; Table 1), but can also form cystathionine and sulfide with homocysteine and cysteine via $\beta$-replacement reaction, and was capable of producing sulfide via the cysteine desulfurase reaction by hydrolysing cysteine (Figure 3; Table 1). LmjCBS, however, can also form cysteine from OAS and sulfide. The $\mathrm{K}_{\mathrm{cat}} / \mathrm{K}_{\mathrm{m}}$ of LmjCBS towards OAS is $\sim 7$-fold higher than that of LmjCS, however its $\mathrm{K}_{\mathrm{cat}} / \mathrm{K}_{\mathrm{m}}$ for sulfide is some 140 -fold lower (Table 2). This suggests that CS and CBS are adapted to different physiological conditions, in which the relative concentrations of the two substrates are changed. Unfortunately, there is little or no information on the concentration of the two substrates in the various developmental stages of the parasite. However, there is some evidence that amastigotes have increased capacities for $\beta$-oxidation, the TCA cycle, mitochondrial electron transport and oxidative phosphorylation $[2,46]$. This could result in increased availability of acetyl COA for OAS synthesis and a decreased availability of sulfide due to increased utilisation for the synthesis of iron sulfur clusters and lipoic acid. Under these circumstances, one would predict that CS rather than CBS would be functional in de novo cysteine biosynthesis. However, these speculative suggestions need to be rigorously tested experimentally.

Other CBSs also have CS activity. Human CBS, previously thought to lack CS activity [47], has recently been reported to have such activity but with a very low catalytic efficiency of $\mathrm{K}_{\mathrm{cat}} / \mathrm{K}_{\mathrm{m}} 135 \mathrm{~s}^{-1} \mathrm{M}^{-1}$ [48]. The difference between HsCBS and CBS from lower eukaryotes (which have significant CS activity, detailed below) is thought to be due to the active site pocket of HsCBS being constricted by the Nterminal haem-binding and C-terminal regulatory domains (Figure S1C) - such that it cannot accommodate the large acetyl group of OAS at its serine-binding site; whereas CBSs lacking one or other of domains can [48]. The CBSs from T. cruzi (TcCBS) and $S$. cerevisiae (ScCBS) have significantly greater $\mathrm{CS}$ activities than $\mathrm{HsCBS}$, with the $\mathrm{K}_{\mathrm{cat}}$ for OAS being $12.5 \mathrm{sec}^{-1}$ and $19.2 \mathrm{sec}^{-1}$, respectively, and $\mathrm{K}_{\mathrm{m}} \mathrm{S}$ of 4.9 $\mathrm{mM}$ and $1.3 \mathrm{mM}$ for OAS and $4.1 \mathrm{mM}$ and $16.6 \mathrm{mM}$ for sodium sulfide, respectively $[5,8]$. These $\mathrm{K}_{\mathrm{cat}}$ values are similar to those of the CBS activities of the same enzymes [43]. This is a very different situation from the L. major CBS, which has a CS activity 
23-fold higher than its CBS activity (Table 2). We suggest that the explanation for the much higher CS activity of LmjCBS is that it lacks both the $\mathrm{N}$ - and C-terminal extensions that in the human enzyme constrict entry to the active site cleft, whereas both ScCBS and TcCBS have one of these extensions (Figure S1C). Interestingly, only three of the eight $T$. cruzi CBS genes have an $\mathrm{N}$-terminal extension (www.geneDB.org), and the isoform with the longest extension is the one characterised [5]. The other T. cruzi CBS isoforms encoded in the genome (www.geneDB.org) may have more similar biochemical properties to the L. major CBS.

The functional significance of the multiple reactions carried out by L. major CBS is unknown but the kinetic parameters of this protein do not rule out that these reactions potentially occur within the cell and may confer selective advantage and flexibility to parasite within its hosts. The possibility that CBS functionally acts in vivo as a CS cannot yet be ruled out. Indeed, the finding that the T. cruzi CBS gene can overcome a growth defect of both $S$. cerevisiae (WB63yCBS $\triangle$ lines- deficient in CBS) and Escherichia coli (NK3 lines- a double mutant deficient the bacterial type A (cysK) and type B (cysM) CSs) suggests that this trypanosomatid CBS can functionally act as a CBS and a CS in vivo [5]. Thus L. major CBS has both CS and CBS activities, and this clearly distinguishes it from LmjCS in that the latter has no detectable CBS activity.

Western analyses showed that CS and CBS are both present in promastigotes of $L$. major (Figure 5), data confirmed for other Leishmania species by the global proteomic analyses reported to date - with there being some evidence of protein levels changing between different developmental stages [46]. In an attempt to unravel which pathways operate in promastigotes, we carried out the experiments monitoring parasite growth when different sulfur amino acids are available exogenously (Figure 5). These experiments showed that the parasite does not benefit significantly from an exogenous source of cysteine, in contrast to report for T. brucei [4]. Interestingly, however, methionine promoted growth (Figure 5) which correlates with a previous report that is is transported into promastigotes and augments the amino acid pool; importantly it is used predominatly for cystathionine biosynthesis [49]. Our data on intracellular thiol levels confirm this in that addition of exogenous methionine results in thiol levels including cysteine relatively similar to those in normal promastigotes grown in full medium, presumably from conversion of methionine via the transsulfuration pathway, whereas addition of exogenous cysteine had little effect on intracellular cysteine levels, although glutathione and trypanothione levels were relatively similar to those in cells grown in normal medium (Figure $5 \mathrm{C}_{\mathrm{i}}$ ). These data suggested that, unlike methionine, cysteine may not be transported at a sufficient rate to maintain the intracellular pool of cysteine at the level required for normal growth.

Our transport data (Figure 6) confirm this, for although transport occurred its rate was some 200 -fold lower than cysteine transport into T. brucei [50] and the $\mathrm{K}_{\mathrm{m}}$ for cysteine is some 10-fold higher than that for transport of methionine into Leishmania [40]. The low $V_{\max }$ for transport of cysteine coupled with the $K_{m}$ of $>200 \mu \mathrm{M}$, when the concentration of cysteine in the medium is about $70 \mu \mathrm{M}$, is likely to mean that this is not a mechanism used by the parasite for obtaining cysteine. The importance of the cysteine de novo biosynthetic pathway was reiterated by the observation that promastigotes in medium lacking an exogenous organic source of sulfur had an upregulated level of CS (Figure 5D), presumably in an attempt to counter the lack of intracellular cysteine. Thus our results show that Leishmania differs considerably not 
only from $T$. brucei, which relies upon exogenous cysteine [4,50], but also T. cruzi, which transports cysteine via a highly specific transporter with a relatively low $\mathrm{K}_{\mathrm{m}}$ $(49 \mu \mathrm{M})$ to maintain its intracellular cysteine pool and iron-sulfur formation [51]. Our growth data (Figure 5A) also confirmed that serine was an essential amino acid for Leishmania that is salvaged by promastigotes and used for growth [38]. This is consistent with the absence from its genome of genes involved in serine biosynthesis [52]. Together these data are consistent with both the CS and CBS pathways operating in promastigotes and that methionine can be converted to cysteine, thus suggesting that CBS certainly functions in cystathionine synthesis in vivo.

A key question is why Leishmania has two pathways for generating cysteine when many cells cope very well with just a single source. One likely explanation is the availability of exogenous nutrients differs considerably between the parasite's environments in its sandfly and mammalian hosts and that the potential for two functional synthetic routes in the parasite reflects this. For instance, maybe de novo synthesis via CS occurs in one stage and synthesis from methionine occurs in another. The generation of genetic mutants lacking key genes could be an informative approach to answer these questions. A second possibility is that the two routes occur in different sub-cellular compartments within Leishmania. However, neither CS nor SAT contains clear targeting signals for location to organelles and preliminary evidence suggests both are cytosolic. It would be interesting to investigate whether intentionally targeting them to an organelle would have any impact upon cysteine homeostasis in the parasite.

As CS is absent from humans and L. major CBS is divergent from the mammalian homologue, both proteins potentially could represent good drug targets. The discovery that the ten C-terminal residues of SAT are inhibitory to CS [53] could form a framework for which specific inhibitors of CS can be designed, whereas the ability of L. major CBS to use more bulky substrates than can the human enzyme suggests a way to specifically target the parasite CBS.

Acknowledgements. We thank Professor Rudiger Hell, Heidelberg Institute of Plant Sciences, University of Heidelberg, Germany for the pET3dAtOASTL and pET28a ${ }^{+}$SAT plasmids used in this study. We thank Professor Sylke Müller (University of Glasgow) for assistance with the thiol analytical methodology and very helpful comments on the manuscript, Professor Mike Barrett and Ms Isabel Vincent (University of Glasgow) and Ms Kirstyn Brunker (University of Strathclyde) for their help with the cysteine transport assays and HPLC analyses, respectively.

Funding. This study was funded by the Medical Research Council.

\section{References}

1. Croft, S. L. and Yardley, V. (2002) Chemotherapy of leishmaniasis. Curr.Pharm.Des 8,319-342

2. Opperdoes, F. R. and Coombs, G. H.(2007) Metabolism of Leishmania: proven and predicted. Trends Parasitol. 23,49-158 
3. Krauth-Siegel, R. L. and Comini, M. A. (2008) Redox control in trypanosomatids, parasitic protozoa with trypanothione-based thiol metabolism. Biochim.Biophys.Acta 1780,1236-1248

4. Duszenko, M., Muhlstadt, K. and Broder, A. (1992) Cysteine is an essential growth factor for Trypanosoma brucei bloodstream forms. Mol Biochem.Parasitol. 50,269-273

5. Nozaki, T., Shigeta, Y., Saito-Nakano, Y., Imada, M. and Kruger, W. D.(2001) Characterization of transsulfuration and cysteine biosynthetic pathways in the protozoan hemoflagellate, Trypanosoma cruzi. Isolation and molecular characterization of cystathionine beta-synthase and serine acetyltransferase from Trypanosoma. J.Biol.Chem. 276,6516-6523

6. Ali, V. and Nozaki, T. (2007) Current therapeutics, their problems, and sulfurcontaining-amino-acid metabolism as a novel target against infections by "amitochondriate" protozoan parasites. Clin.Microbiol.Rev. 20,164-187

7. Muller, S., Liebau, E., Walter, R. D. and Krauth-Siegel, R. L.. (2003) Thiolbased redox metabolism of protozoan parasites. Trends Parasitol. 19,320-328

8. Ono, B., Kijima, K., Inoue, T., Miyoshi, S., Matsuda, A. and Shinoda, S. (1994) Purification and properties of Saccharomyces cerevisiae cystathionine beta-synthase. Yeast 10,333-339

9. Hell, R., Jost, R., Berkowitz, V. and Wirtz, M. (2002) Molecular and biochemical analysis of the enzymes of cysteine biosynthesis in the plant Arabidopsis thaliana. Amino.Acids 22,245-257

10. Chattopadhyay, A., Meier, M., Ivaninskii, S., Burkhard, P., Speroni, F., Campanini, B., Bettati, S., Mozzarelli, A., Rabeh, W. M., Li, L. and Cook, P. F. (2007) Structure, mechanism, and conformational dynamics of Oacetylserine sulfhydrylase from Salmonella typhimurium: comparison of A and $\mathrm{B}$ isozymes. Biochemistry 46,8315-8330

11. Westrop, G. D., Goodall, G., Mottram, J. C. and Coombs, G. H. (2006) Cysteine biosynthesis in Trichomonas vaginalis involves cysteine synthase utilizing O-phosphoserine. J.Biol.Chem. 281,25062-25075

12. Williams, R. A., Kelly, S. M., Mottram, J. C. and Coombs, G. H. (2003) 3Mercaptopyruvate sulfurtransferase of Leishmania contains an unusual Cterminal extension and is involved in thioredoxin and antioxidant metabolism. J.Biol.Chem. 278,1480-1486

13. Medina-Acosta, E. and Cross, G. A. (1993) Rapid isolation of DNA from trypanosomatid protozoa using a simple 'mini-prep' procedure. Mol Biochem.Parasitol. 59,327-329

14. Wirtz, M., Berkowitz, O., Droux, M. and Hell, R. (2001) The cysteine synthase complex from plants. Mitochondrial serine acetyltransferase from Arabidopsis thaliana carries a bifunctional domain for catalysis and proteinprotein interaction. Eur.J.Biochem. 268,686-693 
15. Kredich, N. M. and Tomkins, G. M.(1966) The enzymic synthesis of Lcysteine in Escherichia coli and Salmonella typhimurium. J.Biol.Chem. 241,4955-4965

16. Flint, D. H., Tuminello, J. F. and Miller, T. J. (1996) Studies on the synthesis of the Fe-S cluster of dihydroxy-acid dehydratase in escherichia coli crude extract. Isolation of O-acetylserine sulfhydrylases A and B and betacystathionase based on their ability to mobilize sulfur from cysteine and to participate in Fe-S cluster synthesis. J.Biol.Chem. 271,16053-16067

17. Mino, K., Imamura, K., Sakiyama, T., Eisaki, N., Matsuyama, A. and Nakanishi, K. (2001) Increase in the stability of serine acetyltransferase from Escherichia coli against cold inactivation and proteolysis by forming a bienzyme complex. Biosci.Biotechnol.Biochem. 65,865-874

18. Denton, H., McGregor, J. C. and Coombs, G. H. (2004) Reduction of antileishmanial pentavalent antimonial drugs by a parasite-specific thioldependent reductase, TDR1. Biochem.J. 381,405-412

19. Al Salabi,M.I. and de Koning,H.P. (2005) Purine nucleobase transport in amastigotes of Leishmania mexicana: involvement in allopurinol uptake. Antimicrob. Agents Chemother. 49, 3682-3689

20. Hindson, V. J., Moody, P. C., Rowe, A. J. and Shaw, W. V. (2000) Serine acetyltransferase from Escherichia coli is a dimer of trimers. J.Biol.Chem. 275,461-466

21. Zhu, X., Yamaguchi, T. and Masada, M. (1998) Complexes of serine acetyltransferase and isozymes of cysteine synthase in spinach leaves. Biosci.Biotechnol.Biochem. 62,947-952

22. Ruffet, M. L., Lebrun, M., Droux, M. and Douce, R. (1995) Subcellular distribution of serine acetyltransferase from Pisum sativum and characterization of an Arabidopsis thaliana putative cytosolic isoform. Eur.J.Biochem. 227,500-509

23. Vaara, M. 1992. Eight bacterial proteins, including UDP-N-acetylglucosamine acyltransferase (LpxA) and three other transferases of Escherichia coli, consist of a six-residue periodicity theme. FEMS Microbiol.Lett. 76,249-254

24. Byrne, C. R., Monroe, R. S., Ward, K. A. and Kredich, N. M. (1988) DNA sequences of the cysK regions of Salmonella typhimurium and Escherichia coli and linkage of the cysK regions to ptsH. J.Bacteriol. 170,3150-3157

25. Claus, M. T., Zocher, G. E., Maier, T. H. and Schulz, G. E. (2005) Structure of the O-acetylserine sulfhydrylase isoenzyme CysM from Escherichia coli. Biochemistry 44,8620-8626

26. Oda, Y., Mino, K., Ishikawa, K. and Ataka, M. (2005) Three-dimensional structure of a new enzyme, O-phosphoserine sulfhydrylase, involved in 1cysteine biosynthesis by a hyperthermophilic archaeon, Aeropyrum pernix K1, at 2.0A resolution. J.Mol Biol. 351,334-344 
27. Bonner, E. R., Cahoon, R. E., Knapke, S. M. and Jez, J. M. (2005) Molecular basis of cysteine biosynthesis in plants: structural and functional analysis of O-acetylserine sulfhydrylase from Arabidopsis thaliana. J.Biol.Chem. 280,38803-38813

28. Liszewska, F., Lewandowska, M., Plochocka, D. and Sirko, A. (2007) Mutational analysis of O-acetylserine (thiol) lyase conducted in yeast twohybrid system. Biochim.Biophys.Acta 1774,450-455

29. Droux, M., Ruffet, M. L., Douce, R. and Job, D. (1998) Interactions between serine acetyltransferase and O-acetylserine (thiol) lyase in higher plants structural and kinetic properties of the free and bound enzymes. Eur.J.Biochem. 255,235-245

30. Alexander, F. W., Sandmeier, E., Mehta, P. K. and Christen, P. (1994) Evolutionary relationships among pyridoxal-5'-phosphate-dependent enzymes. Regio-specific alpha, beta and gamma families. Eur.J.Biochem. 219,953-960

31. Bateman, A. 1997. The structure of a domain common to archaebacteria and the homocystinuria disease protein. Trends Biochem.Sci. 22,12-13

32. Banerjee, R. and Zou, C. G. (2005) Redox regulation and reaction mechanism of human cystathionine-beta-synthase: a PLP-dependent hemesensor protein. Arch.Biochem.Biophys. 433,144-156

33. Jhee, K. H., McPhie, P. and Miles, E. W. (2000) Domain architecture of the heme-independent yeast cystathionine beta-synthase provides insights into mechanisms of catalysis and regulation. Biochemistry 39,10548-10556

34. Maclean, K. N., Janosik, M., Oliveriusova, J., Kery, V. and Kraus, J. P.(2000) Transsulfuration in Saccharomyces cerevisiae is not dependent on heme: purification and characterization of recombinant yeast cystathionine betasynthase. J.Inorg.Biochem. 81,161-171

35. Meier, M., Janosik, M., Kery, V., Kraus, J. P. and Burkhard, P. (2001) Structure of human cystathionine beta-synthase: a unique pyridoxal 5'phosphate-dependent heme protein. EMBO J. 20,3910-3916

36. Stipanuk, M. H. (2004) Sulfur amino acid metabolism: pathways for production and removal of homocysteine and cysteine. Annu.Rev.Nutr. 24,539-577

37. Wirtz, M. and Hell, R. (2006) Functional analysis of the cysteine synthase protein complex from plants: structural, biochemical and regulatory properties. J.Plant Physiol 163,273-286

38. Scott, D. A., Hickerson, S. M., Vickers, T. J. and Beverley, S. M. (2008) The role of the mitochondrial glycine cleavage complex in the metabolism and virulence of the protozoan parasite Leishmania major. J.Biol.Chem. 283,155165 
39. Ariyanayagam,M.R. and Fairlamb,A.H. (2001) Ovothiol and trypanothione as antioxidants in trypanosomatids. Mol. Biochem. Parasitol. 115,189-198

40. Mukkada,A.J. and Simon,M.W. (1977) Leishmania tropica: uptake of methionine by promastigotes. Exp. Parasitol. 42,87-96.

41. Feldman-Salit, A., Wirtz, M., Hell, R. and Wade, R. C. (2008) A Mechanistic Model of the Cysteine Synthase Complex. J.Mol Biol. 386,37-59

42. Huang, B., Vetting, M. W. and Roderick, S. L. (2005) The active site of Oacetylserine sulfhydrylase is the anchor point for bienzyme complex formation with serine acetyltransferase. J.Bacteriol. 187,3201-3205

43. Mino, K. and Ishikawa, K. (2003) Characterization of a novel thermostable Oacetylserine sulfhydrylase from Aeropyrum pernix K1. J.Bacteriol. 185,22772284

44. Bogdanova, N. and Hell, R. (1997) Cysteine synthesis in plants: proteinprotein interactions of serine acetyltransferase from Arabidopsis thaliana. Plant J. 11,251-262

45. Mino, K., Yamanoue, T., Sakiyama, T., Eisaki, N., Matsuyama, A. and Nakanishi, K. (2000) Effects of bienzyme complex formation of cysteine synthetase from escherichia coli on some properties and kinetics. Biosci.Biotechnol.Biochem. 64,1628-1640

46. Rosenzweig, D., Smith, D., Opperdoes, F., Stern, S., Olafson, R. W. and Zilberstein, D. (2008) Retooling Leishmania metabolism: from sand fly gut to human macrophage. FASEB J. 22,590-602

47. Braunstein, A. E., Goryachenkova, E. V., Tolosa, E. A., Willhardt, I. H. and Yefremova, L. L. (1971) Specificity and some other properties of liver serine sulphhydrase: evidence for its identity with cystathionine -synthase. Biochim.Biophys.Acta 242,247-260

48. Frank, N., Kent, J. O., Meier, M. and Kraus, J. P. (2008) Purification and characterization of the wild type and truncated human cystathionine betasynthase enzymes expressed in E. coli. Arch.Biochem.Biophys. 470,64-72

49. Mukkada, A.J. and Simon, N.W. (1977) Leishmania tropica: uptake of methionine by promastigotes.Exp Parasitol.42,87-96

50. Duszenko,M., Ferguson,M.A., Lamont,G.S., Rifkin,M.R., and Cross,G.A. (1985). Cysteine eliminates the feeder cell requirement for cultivation of Trypanosoma brucei bloodstream forms in vitro. J. Exp. Med. 162,1256-1263.

51. Canepa,G.E., Bouvier,L.A., Miranda,M.R., Uttaro,A.D., and Pereira,C.A. (2009). Characterization of Trypanosoma cruzi L-cysteine transport mechanisms and their adaptive regulation. FEMS Microbiol. Lett. 292,27-32

52. Dos Santos, M.G., Paes, L.S., Zampieri, R.A., da Silva M.F., Silber, A.M. and Floeter-Winter, L.M. (2009) Biochemical characterization of serine transport 
in Leishmania (Leishmania) amazonensis. Mol Biochem. Parasitol. 163,107113

53. Kumaran, S. and Jez, J. M. (2007) Thermodynamics of the interaction between $\mathrm{O}$-acetylserine sulfhydrylase and the $\mathrm{C}$-terminus of serine acetyltransferase. Biochemistry 46,5586-5594

\section{Figure legends}

Figure 1. Cysteine biosynthesis pathways in L. major. Enzymes present in $L$. major and the reactions they catalysed identified by in silico analysis using BLAST algorithmn are given with their geneDB systematic name. Key:- CS, cysteine synthase; SAT, serine acetyltransferase; CBS, cystathionine $\beta$-synthase; CGL, cystathionine $\gamma$-lyase; CBL, cystathionine $\beta$-lyase; CGS, cystathionine $\gamma$-synthase.

Figure 2. Activity of enzymes potentially involved in the de novo biosynthesis of cysteine. Relationship between the cysteine synthase activity and the sulfide produced from the action of mercaptopyruvate sulfurtransferase on different concentrations of 3-mercaptopyruvate. The reaction mixture containing 3-mercaptopyruvate, $\beta$ mercaptoethanol $(5 \mathrm{mM})$ and $0.5 \mu \mathrm{g}$ rLmjMST was incubated for 5 min prior to addition of $O$-acetylserine $(30 \mathrm{mM})$ and $0.5 \mu \mathrm{gmjCS}$ and further incubation for 5 min. The amount of cysteine produced was quantified as described by [15]

Figure 3. A general scheme of reactions catalysed by LmjCBS. Substrates used by the enzyme to synthesize cystathionine and cysteine as well as degrade cysteine are given. Key to reactions: I, cystathionine $\beta$-synthase; II, homocysteine desulfurase; III, cysteine synthase; IV, serine sulfydrase; $\mathrm{V}$, cysteine desulfurase.

Figure 4. The LmjSAT-LmjCS complex from L. major. (A) His-LmjSAT copurified with untagged LmjCS and analysed by SDS-PAGE analysis including staining with Coomassie blue. Lanes 1 shows the proteins eluted with $1 \mathrm{M}$ imidazole under denaturing conditions; they are consistent with there being a LmajSAT-LmajCS complex. (Bi) Western blot analysis using $\alpha$-His and $\alpha$-LmjCS on eluants from affinity chromatography of LmjSAT in complex with LmjCS and eluted with $500 \mathrm{mM}$ imidazole (lane 1) or first treated with wash buffer containing 10 mM OAS (lane 3) and subsequently with $500 \mathrm{mM}$ imidazole (lane 4). Lane 2 shows the eluant from lysates of E. coli expressing rLmjSAT alone. (Bii) SDS-PAGE analysis including staining with Coomassie blue of eluants from affinity chromatography of AtSAT in complex with LmjCS (lane 1), LmjCS(K222A) (lane 2) and LmjCS (H226A/K227A) (lane 3). Molecular masses $(\mathrm{kDa})$ are shown on the left. (Ci). Sequence alignment of LmjCS (this study), AtOASTL [9] and TvCS [11] showing positively charged residues involved in SAT binding marked with asterisks; they were subsequently replaced with an alanine by site-directed mutagenesis to generate the mutants LmjCS(K222A) and LmjCS(H226A/K227A). (Cii) Western blot analysis using $\alpha-$ LmjSAT and $\alpha$-LmjCS on eluants from affinity chromatography of LmjSAT (shown in top panel) in complex with various CS proteins (bottom panel) and eluted with $1 \mathrm{M}$ imidazole. $\alpha$-LmjCS recognises AtOASTL and TvCS. Key: LmjCS (lane 1), LmjCS(K222A) (lane 2), LmjCS(H226A/K227A) (lane 3), AtOASTL (lane 4), 
AtOASTL(K217A) (lane 5) and TvCS (lane 6). Molecular masses (kDa) are shown on the left.

\section{Figure 5. Cell density and thiol levels of $L$. major promastigotes in sulfur}

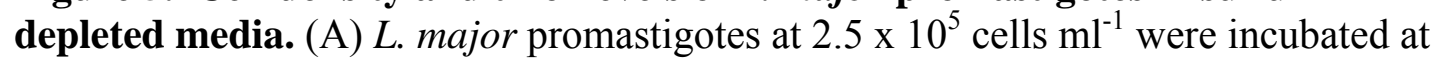
$27^{\circ} \mathrm{C}$ for 5 days in SDM medium (lacking an exogenous sulfur source) and supplemented with cysteine $(300 \mu \mathrm{M})$, methionine $(300 \mu \mathrm{M})$, thiosulfate $(150 \mu \mathrm{M})$, or serine $(300 \mu \mathrm{M})$. The cell densities were determined initially (represented by grey dashed lines) and at day 5 (black bars). Data are mean \pm SE from 3 independent experments. (B) Experiments were carried out as detailed in (A) but all treatments were supplemented with serine at $300 \mu \mathrm{M}$ to give SSDM. Additional supplements were $O$-acetylserine (OAS, $250 \mu \mathrm{M}$ ) or 3-mercaptopyruvate (3-MP, $180 \mu \mathrm{M})$. Data are means \pm SE from 2 independent experiments. (Ci) Total thiol content of L. major grown under different conditions: RPMI alone (1), RPMI supplemented with $300 \mu \mathrm{M}$ methionine (2) or cysteine (3); HOMEM medium (4). Results are means \pm S.D. from 3 extracts. (Cii) Intracellular levels of cysteine, trypanathione and glutathione of $L$. major grown under conditions as in Ci. Results are means \pm S.D. from 3 extracts. (Di) Western blot analysis of lysates of promastigotes from (B). SSDM (lane 1), HOMEM nutrient-rich medium (lane 2), SSDM supplemented with cysteine (lane 3) and SSDM supplemented with methionine (lane 4). Molecular masses (kDa) are shown on the left. (ii) Densitometric analysis of signals from LmjCBS compared with TDR1 (top panel) and LmjCS compared with TDRI (bottom panel) using ImageJ software (http://rsb.info.nih.gov/ij/index.html).

Figure 6. Cysteine transport in L. major promastigotes. (A) Time dependence of cysteine incorporation using $50 \mathrm{nM}\left[{ }^{35} \mathrm{~S}\right]$-L-cysteine and $25 \mu \mathrm{M}$ non-radioactive cysteine with $2 \times 10^{7}$ promastigotes. Cysteine incorporation was linear for $5 \mathrm{~min}$ (insert). (B) Transport of cysteine during 5 min as a function of cysteine concentration. The experiment involved $2 \times 10^{7}$ promastigotes and various concentrations of cysteine, in all cases provided from a stock solution of $50 \mathrm{nM}\left[{ }^{35} \mathrm{~S}\right]-$ L-cysteine and $500 \mu \mathrm{M}$ non-radioactive cysteine. The reciprocal plot is shown in the inset. 
Table 1. Genes identified in the genome of $L$. major orthologous to genes encoding enzymes of cysteine biosynthesis

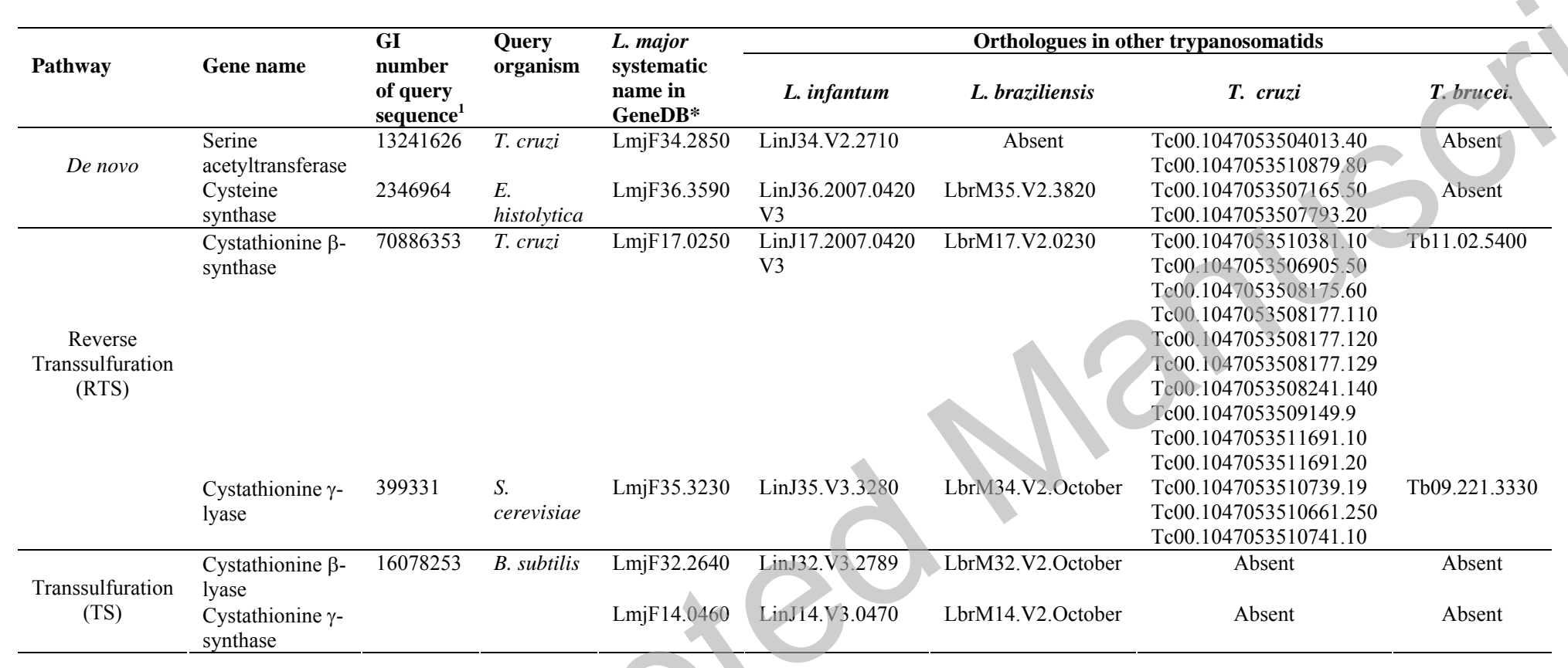

${ }^{1} \mathrm{GI}$ number is a unique series of digits assigned consecutively to each sequence record processed by NCBI (www.ncbi.nlm.nih.gov).

- www.geneDB.org 


\section{Table 2. Kinetic parameters of enzymes of cysteine synthesis}

\begin{tabular}{|c|c|c|c|c|c|}
\hline Enzyme & Activity & Substrates & $\begin{array}{c}\mathrm{K}_{\mathrm{m}} \\
(\mathrm{mM})\end{array}$ & $\begin{array}{c}\mathrm{K}_{\text {cat }} \\
\left(\mathrm{sec}^{-1}\right)\end{array}$ & $\begin{array}{c}\mathrm{K}_{\mathrm{cat}} / \mathrm{K}_{\mathrm{m}} \\
\left(\mathrm{M}^{-1} \sec ^{-1}\right)\end{array}$ \\
\hline \multirow{4}{*}{ LmjCS } & O-acetylserine sulfhydrylase ${ }^{I}$ & O-acetylserine & $17.5 \pm 4.8$ & 2047 & $1.2 \times 10^{5}$ \\
\hline & & Sulfide & $0.13 \pm 0.04$ & 2669 & $2.0 \times 10^{7}$ \\
\hline & Cysteine desulfurase ${ }^{2}$ & Cysteine & $3.1 \pm 0.7$ & 88.2 & $2.9 \times 10^{4}$ \\
\hline & & $\beta$-mercaptoethanol & $13.8 \pm 0.6$ & 99.0 & $7.2 \times 10^{3}$ \\
\hline \multirow{10}{*}{ LmjCBS } & O-acetylserine sulfhydrylase ${ }^{3}$ & O-acetylserine & $1.6 \pm 0.4$ & 2269 & $1.4 \times 10^{6}$ \\
\hline & & Sodium sulfide & $10.7 \pm 0.9$ & 1516 & $1.4 \times 10^{5}$ \\
\hline & Cysteine desulfurase ${ }^{4}$ & Cysteine & $0.8 \pm 0.5$ & 38.3 & $4.8 \times 10^{4}$ \\
\hline & & $\beta$ - mercaptoethanol & $4.4 \pm 1.9$ & 20.7 & $4.7 \times 10^{3}$ \\
\hline & Serine sulfhydrylase ${ }^{5}$ & Serine & $3.0 \pm 1.3$ & 14.2 & $4.7 \times 10^{3}$ \\
\hline & & Sodium sulfide & $6.6 \pm 4.2$ & 14.1 & $2.1 \times 10^{3}$ \\
\hline & Homocysteine sulfhydrylase ${ }^{6}$ & Cysteine & $7.1 \pm 2.0$ & 11.1 & $1.6 \times 10^{3}$ \\
\hline & & Homocyteine & $0.54 \pm 0.10$ & 26.2 & $4.9 \times 10^{4}$ \\
\hline & Cystathionine $\beta$-synthase ${ }^{7}$ & Homocysteine & $6.9 \pm 1.8$ & 97.7 & $1.4 \times 10^{4}$ \\
\hline & & Serine & $1.1 \pm 0.8$ & 51.9 & $4.7 \times 10^{4}$ \\
\hline
\end{tabular}

For kinetic analyses, $\geq 6$ different substrate concentrations were used with at least two replicate assays.

${ }^{1}$ O-acetylserine sulfhydrylase activity of LmjCS: the $\mathrm{K}_{\mathrm{m}}$ for OAS was determined using $3 \mathrm{mM} \mathrm{Na}_{2} \mathrm{~S}$ with 1- $40 \mathrm{mM} \mathrm{OAS}$ and the $\mathrm{K}_{\mathrm{m}}$ for $\mathrm{Na}_{2} \mathrm{~S}$ was determined using $30 \mathrm{mM}$ OAS with 0.1-1 $\mathrm{mM} \mathrm{Na}_{2} \mathrm{~S}$

${ }^{2}$ Cysteine desulfurase activity of LmjCS: the $\mathrm{K}_{\mathrm{m}}$ for cysteine was determined using $50 \mathrm{mM} \beta$ mercaptoethanol with $0.2-20 \mathrm{mM}$ cysteine and the $\mathrm{K}_{\mathrm{m}}$ for $\beta$ - mercaptoethanol was determined using $20 \mathrm{mM}$ cysteine and 0.5-50 $\mathrm{mM} \beta$ - mercaptoethanol.

${ }^{3}$ O-acetylserine sulfhydrylase activity of LmjCBS: the $K_{m}$ for OAS was determined using $3 \mathrm{mM} \mathrm{Na}_{2} \mathrm{~S}$ with 0.1-100 mM OAS and the $\mathrm{K}_{\mathrm{m}}$ for $\mathrm{Na}_{2} \mathrm{~S}$ was determined using $100 \mathrm{mM}$ OAS with 1-3 $\mathrm{mM} \mathrm{Na}_{2} \mathrm{~S}$

${ }^{4}$ Cysteine desulfurase activity of LmjCBS: the $\mathrm{K}_{\mathrm{m}}$ for cysteine was determined using $50 \mathrm{mM} \beta$ mercaptoethanol with 0.1-20 cysteine and the $\mathrm{K}_{\mathrm{m}}$ for $\beta$ - mercaptoethanol was determined using 20 $\mathrm{mM}$ cysteine and 1-50 $\mathrm{mM} \beta$ - mercaptoethanol.

${ }^{5}$ Serine sulfhydrylase activity of LmjCBS: the $\mathrm{K}_{\mathrm{m}}$ for serine was determined using $50 \mathrm{mM} \mathrm{Na}_{2} \mathrm{~S}$ with 1-50 $\mathrm{mM}$ serine and the $\mathrm{K}_{\mathrm{m}}$ for $\mathrm{Na}_{2} \mathrm{~S}$ was determined using $50 \mathrm{mM}$ serine with 1-50 $\mathrm{mM} \mathrm{Na}_{2} \mathrm{~S}$

${ }^{6}$ Homocysteine sulfhydrylase activity of LmjCBS: the $K_{m}$ for cysteine was determined using $0.3 \mathrm{mM}$ homocysteine with 1-5 $\mathrm{mM}$ cysteine and the $\mathrm{K}_{\mathrm{m}}$ for homocysteine was determined using $5 \mathrm{mM}$ cysteine with 0.01-0.3 mM homocysteine. 
${ }^{7}$ Cystathionine $\beta$-synthase of LmjCBS: the $\mathrm{K}_{\mathrm{m}}$ for serine was determined using $50 \mathrm{mM}$ homocysteine with 1-50 mM serine and the $\mathrm{K}_{\mathrm{m}}$ for homocysteine was determined using $50 \mathrm{mM}$ serine with 1-50 $\mathrm{mM}$ homocysteine. 


\section{Serine}

SAT

(Lmj34.2850)

CS

(LmjF36.3590) acetate

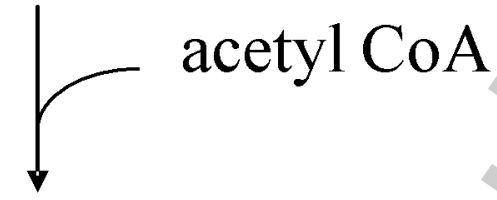

$O$-acetyl serine

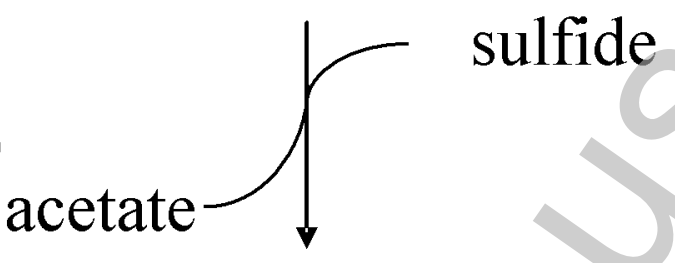

CYSTEINE

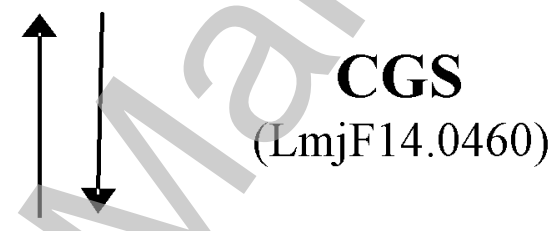

(LmjF35.3230)

Cystathionine

CBS

(LmjF17.0250)

serine

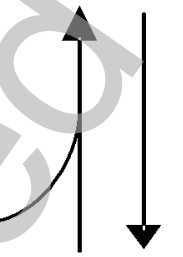

CBL

(LmjF32.2640)

\section{Homocysteine}

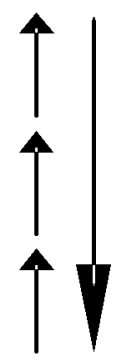

Methionine 


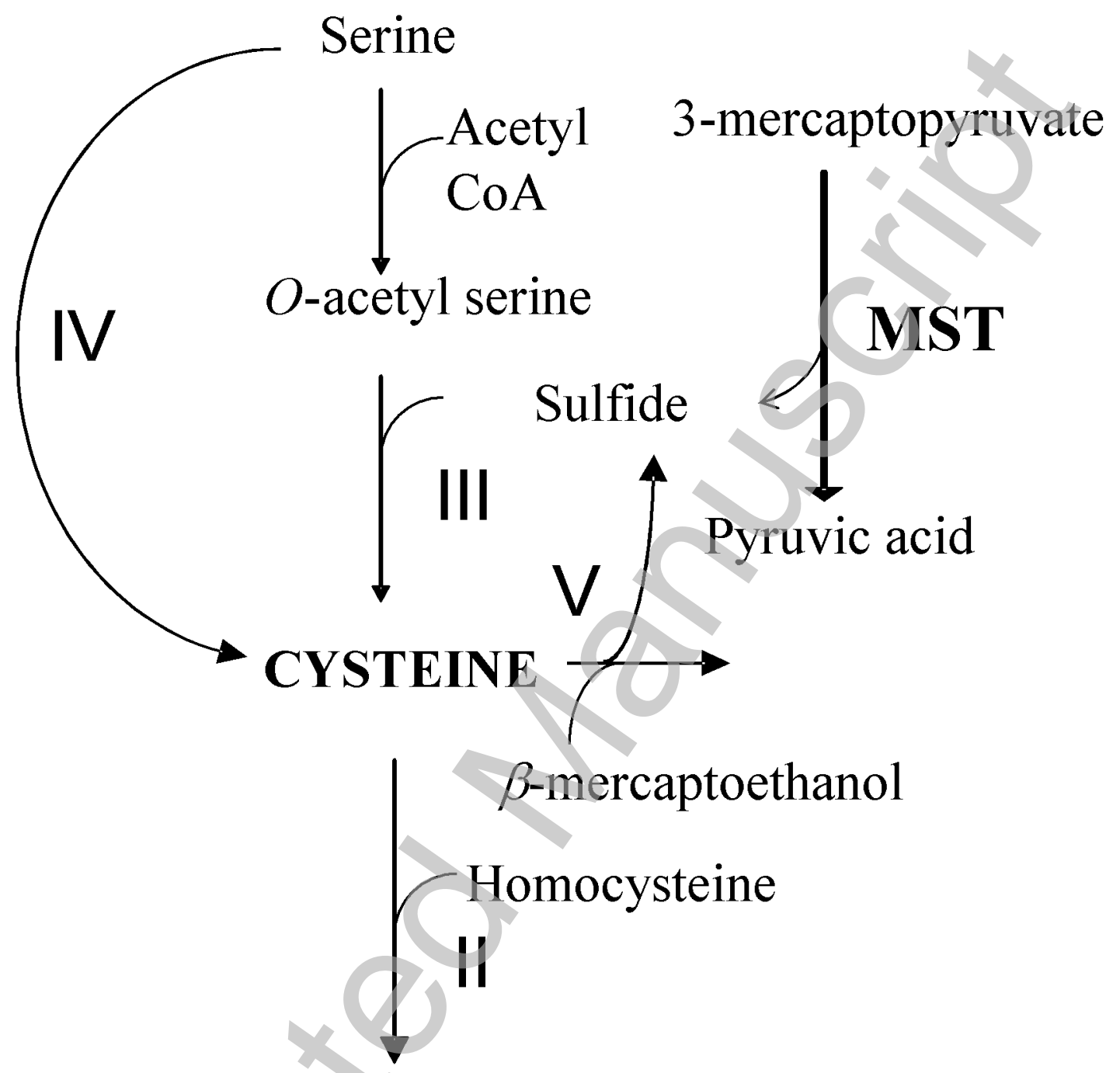

CYSTATHIONINE

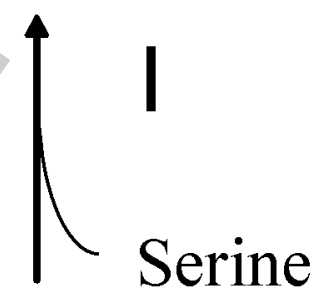

Homocysteine

Figure 3 
A

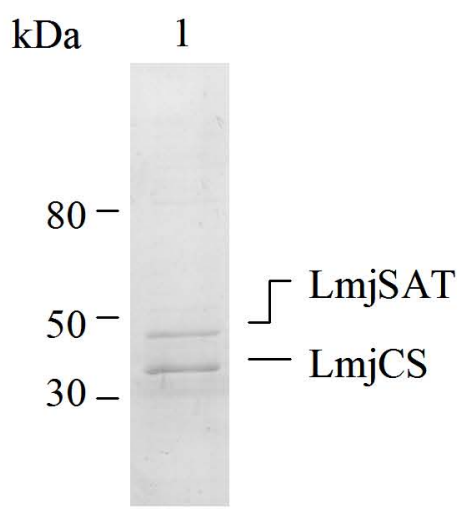

B i

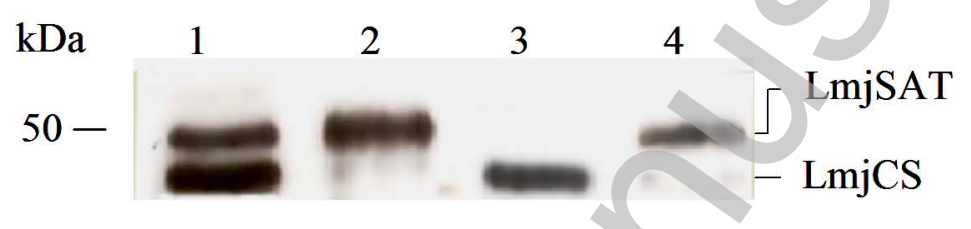

ii

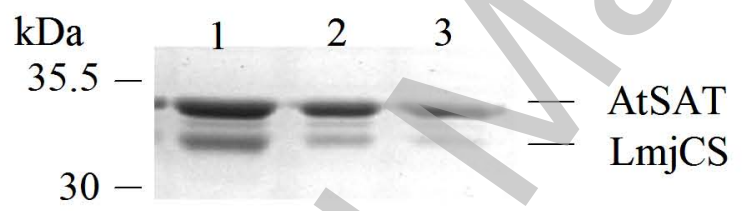

C i

LmjCS (210) VE PMESPVLS GGKPG AHKIQGIG P GF VP

AtOASTL (205) VEPTESAILS GGKPG PHKIQGIG A GFVP

TVCS (202) AQPTKGHY GL------ KS MEE AIVP

ii

$\mathrm{kDa}$

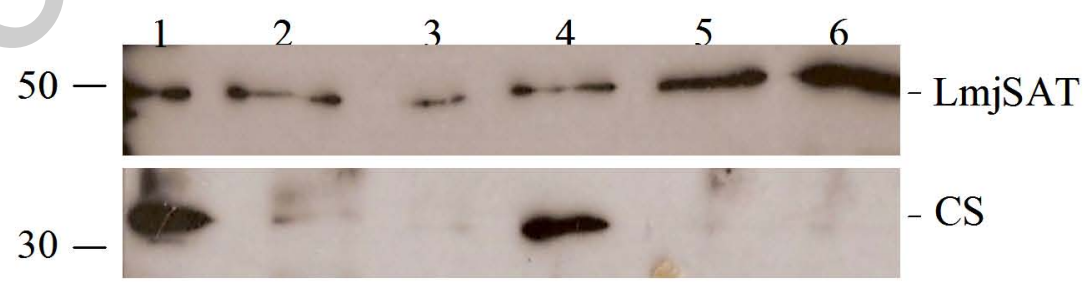

Figure 4 
B Biochemical Journal Immediate Publication. Published on 18 Mar 2009 as manuscript BJ20082441

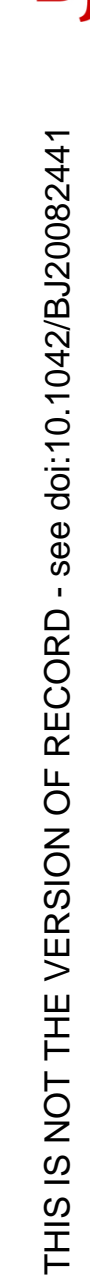

A
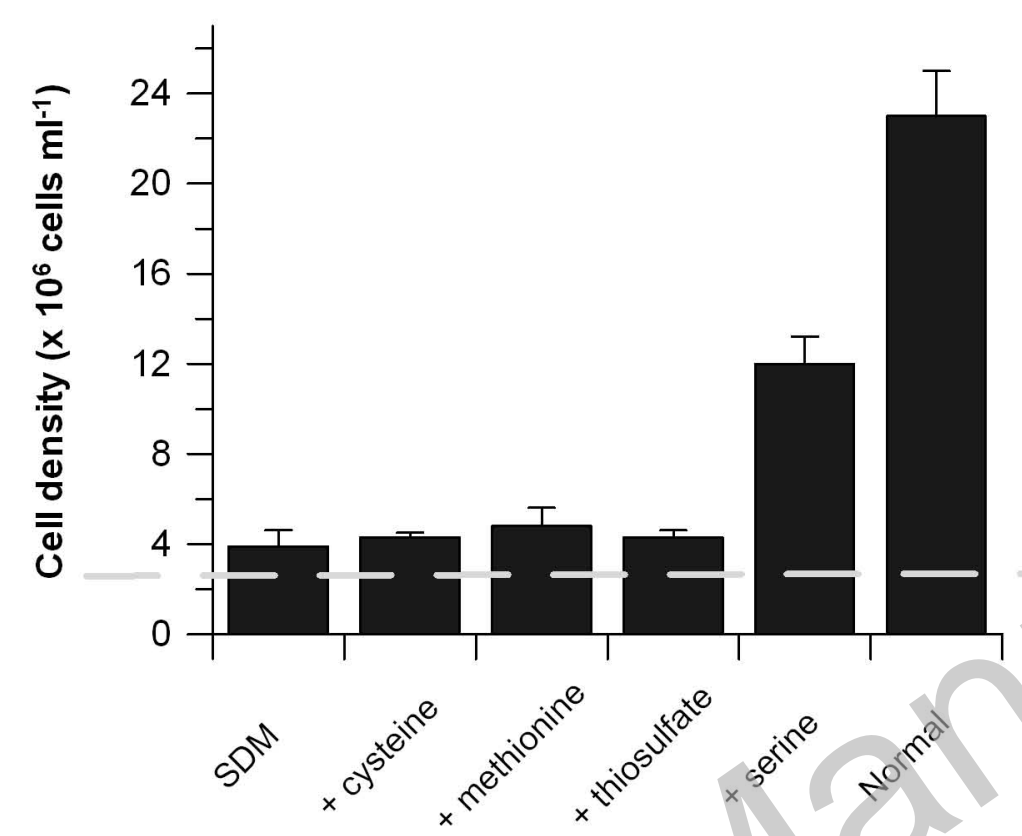

$\mathrm{B}$

Culture conditions
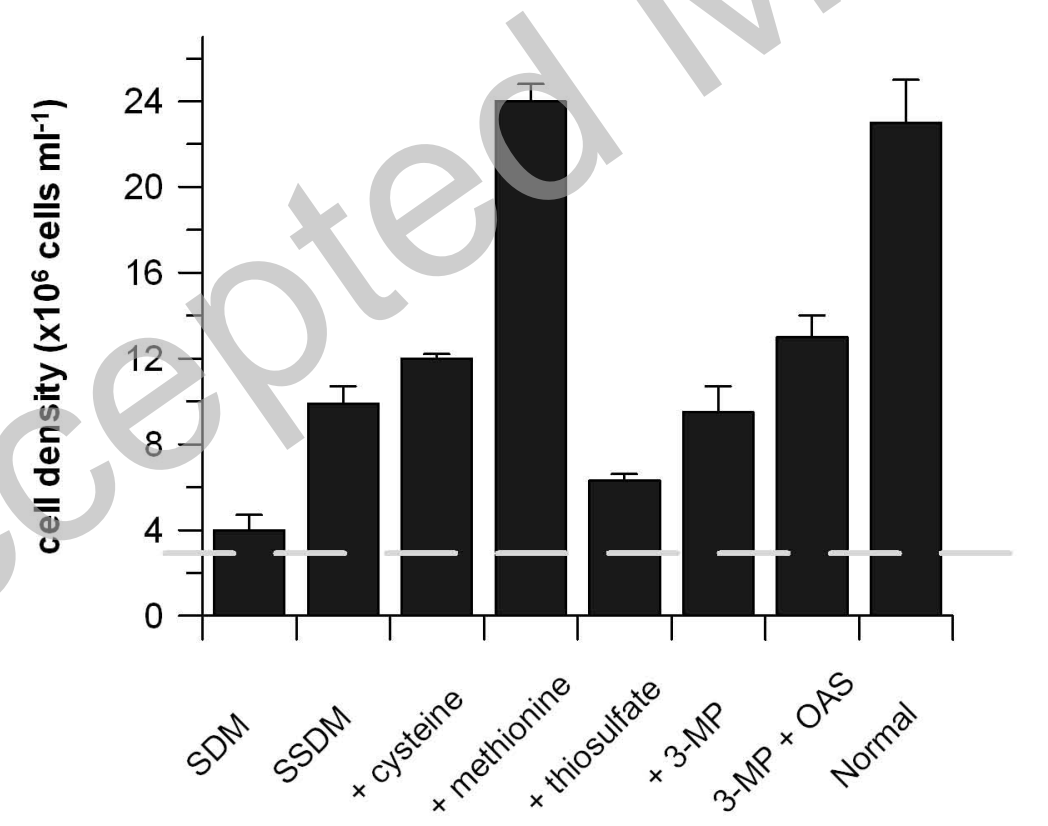

Culture conditions

Licenced copy. Copying is not permitted, except with prior permission and as allowed by law. (c) 2009 The Authors Journal compilation ( 2009 Portland Press Limited 


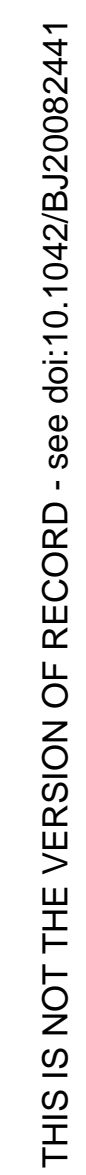

$\mathrm{C}_{\mathrm{i}}$

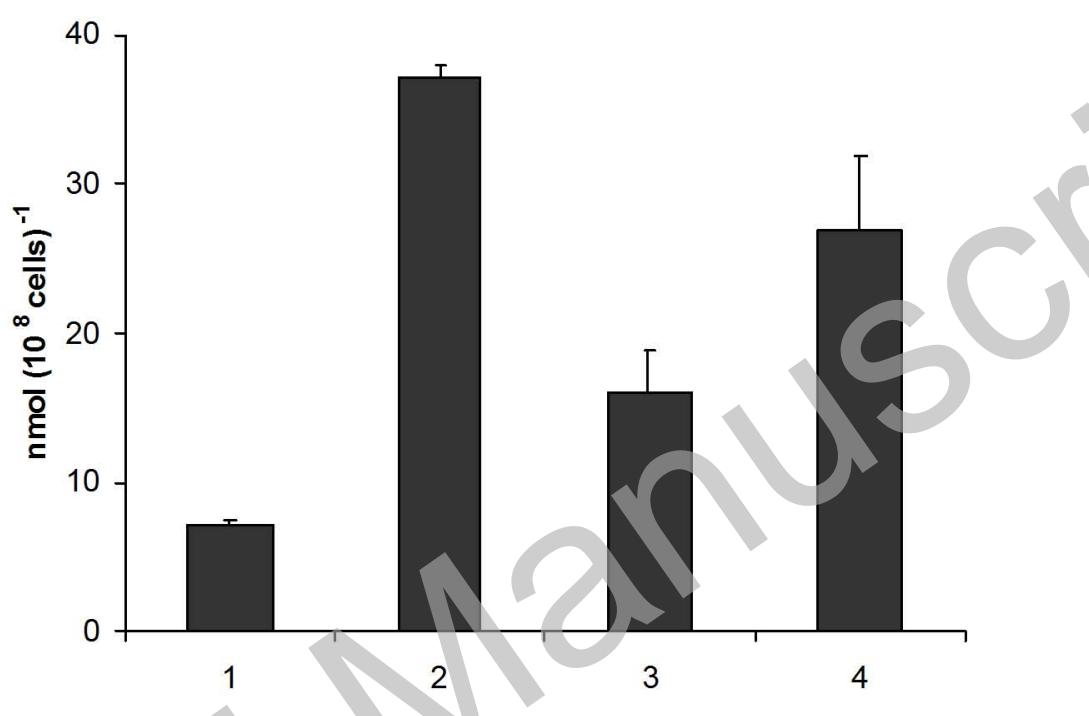

ii

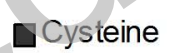

$\square$ Trypanathione

$\square$ Glutathione

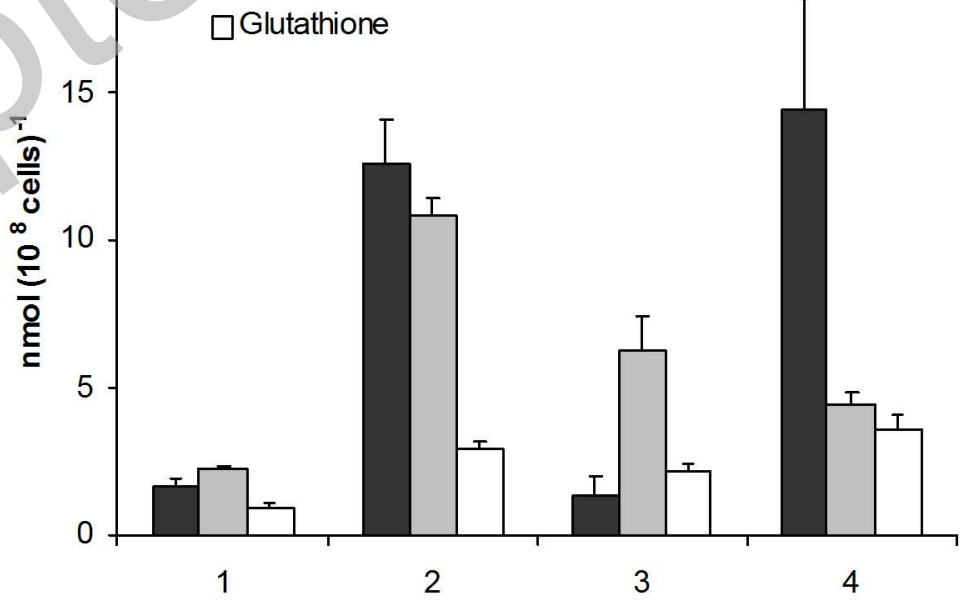

Licenced copy. Copying is not permitted, except with prior permission and as allowed by law. () 2009 The Authors Journal compilation @ 2009 Portland Press Limited 
A

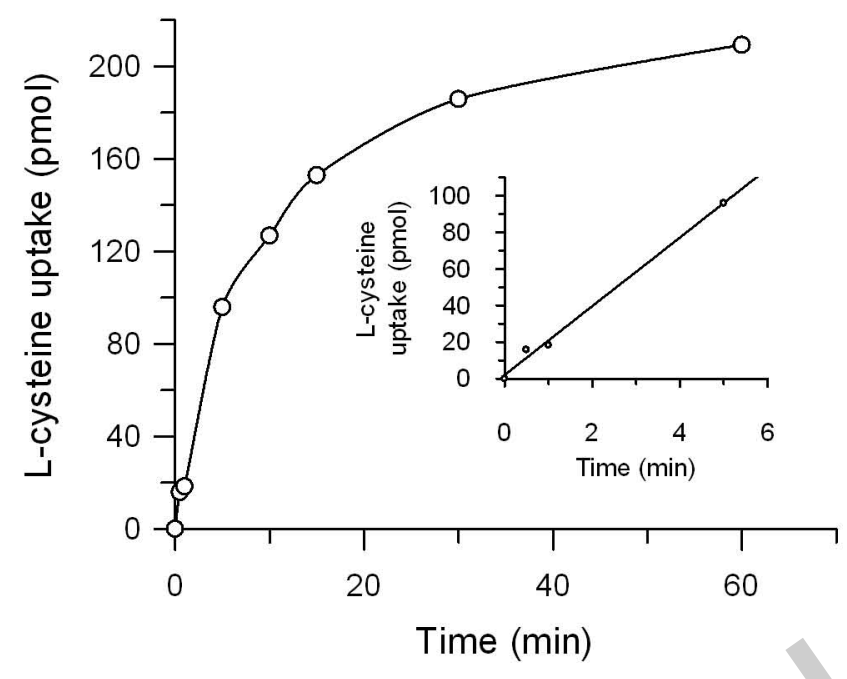

B

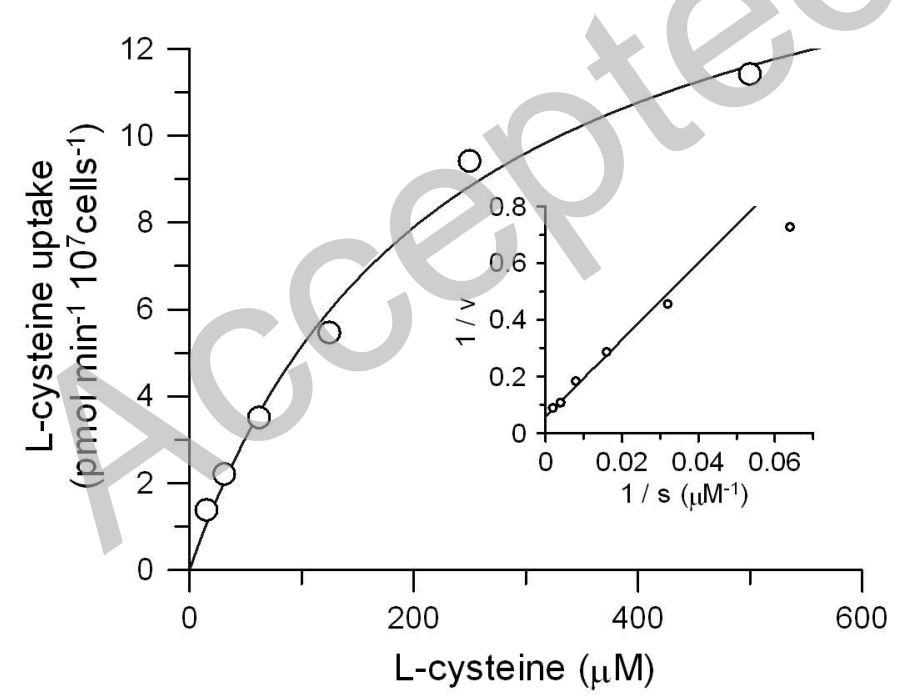

Licenced copy. Copying is not permitted, except with prior permission and as allowed by law. (c) 2009 The Authors Journal compilation ( 2009 Portland Press Limited 